\title{
BEQUEST TAXATION, ESTATE TAXATION, LAND TAXATION, OPTIMUM TOWN, HENRY GEORGE THEOREM AND CAPITAL TAXATION: A SURVEY
}

\author{
Dushko Josheski ${ }^{1}$ Tatjana Boshkov ${ }^{2}$ \\ ${ }^{1}$ Assistant professor Goce Delchev University of Shtip, Faculty of tourism and business logistics, R.North \\ Macedonia, dusko.josevski@ugd.edu.mk \\ ${ }^{2}$ Associate professor, Goce Delchev University of Shtip, Faculty of tourism and business logistics, R.North \\ Macedonia, tatjana.dzaleva@ugd.edu.mk
}

\begin{abstract}
In this paper we make survey of the following models: Bequest taxation model (due to Farhi, Werning (2014)); Estate taxation model (Stiglitz,1978); A case for progressive estate taxation (Farhi, Werning (2010)) Henry George theorem and the optimum size of town (Arnott, Stiglitz (1977)); Optimum town (Mirrlees(1972)); A theory of optimal capital taxation (Piketty, Saez (2012)); A Simpler Theory of Capital Taxation (based on: Saez,Stantcheva, (2016)). The main results are that: bequest taxation is more progressive as $r-g$ is higher, inheritance taxation reduces inequality but only in a case of balanced growth, this result does not hold for two class models, the implicit estate tax is strictly negative and increasing in the parent's productivity; the more unequal distribution of inherited wealth, the higher the optimal tax rate (taxation of capital); taxation of capital is progressive with higher the average relative welfare weight on individuals with capital income higher than $r_{k}$. Inequality of income distribution (unlike inequality from capital income) is desirable even when individuals are identical, when because of economies of scale production centers will be created but with the dispersed residence of workers; in optimum town average costs of the resources equal to marginal resource costs that is Henry George theorem; and there land rent taxation is optimal too; super optimal town aggregate rent exceeds the expenditures on public goods(implying that in super optimal town land taxation is not optimal). These results create one system of theoretical results that later authors may use to prove empirically.
\end{abstract}

Keywords: bequest taxation; estate taxation, Henry George theorem; land taxation, optimal capital taxation JEL: H21; H41

\section{Introduction}

There is substantial controversy in the public debate and among the economists about the proper level of taxation of inherited wealth, see Piketty, Saez (2013). In the dynastic framework of Chamley (1986) and Judd (1985), with no stochastic shocks, the optimal inheritance tax is zero in the long run, because a constant inheritance tax creates a growing distortion on the intertemporal choices. On the other hand, few economists or better say policy makers would comply with this argument. Nowadays, there is a growing concern with the rise of wealth inequality and the threat of creation of oligarchies. Namely, Keynes (1920) also emphasizes the role of "the saving for the sake of savings" in the vast accumulation of capital in the 19th-century Europe: "Europe was so organized socially and economically as to secure the maximum accumulation of capital. While there was some continuous improvement in the daily conditions of life of the mass of the population, society was so framed as to throw a great part of increased income into the control of the class least likely to consume it. The new rich of the nineteenth century were not brought up to larger expenditures and preferred the power which investment gave them to the pleasure of immediate consumption" For the policy makers wealth inequality has been major economic and social problem. New York times columnist and Nobel prize-winning economist Paul Krugman (2019) for instance has lamented the problem and expressed his concern:" we are once again living in an era of extraordinary wealth concentrated in the hands of a few people ... And this concentration of wealth is growing." In an interview from 2014 Nobel prize-winning economist Robert Solow explained the danger from wealth concentration in US: "If that kind of concentration of wealth continues, then we get to be more and more an oligarchical country, a country that's run from the top". The bulk or huge amount of bequests are made of ordinary homes $99 \%$, see Gary-Bobo,Nur(2014). Land and buildings are relatively easy to tax using forms of capital taxation such as property, estate and inheritance levies. The landlords' capital income, that is, rents and imputed rents, are typically taxed. These models include standard Mirrlees (1971) framework where individuals differ in respect with their productivity $\theta$,survival probability $\pi$, and $\beta$ a weight on the taste for future versus present consumption. Saez (2002); Banks and Diamond (2010) has argued that individuals with higher earnings save relatively more, which suggests that high-ability individuals are likely to have a higher taste for savings. But these characteristics are not directly observable $\pi, \theta, \beta$ instead the observables are gross earning during working years and consumption during retirement, so the tax administration uses an individual's inheritance as a separation mechanism, or a tag, when designing an optimal tax system. The classic paper on tagging is Akerlof (1978) (this is somewhat beyond our scope here but it shou be included in another research perhaps). So, in this paper we will review some models on the bequest taxation, estate taxation, land taxation, Henry George theorem and the optimum town theorem, and in the last section we will survey two papers on capital taxation. The main 
purpose of this paper is to survey these papers and to try to tell that these theories are interlinked, and they may be altogether proven empirically in the future.

\section{Literature review}

Piketty (2014), has identified that the gap between the rate of return on capital $r$ and the growth rate of the economy $g$ is a crucial determinant of the long-run evolution of wealth inequality. Looking towards the future, he argues that $r-g$ is likely to be high and that wealth is likely to become more concentrated. Piketty views this scenario as deeply problematic and argues that the only way to prevent its occurrence is to put in place global progressive wealth and bequest taxes. Some of the papers that are built around this idea include: Farhi and Werning (2010, 2013;2014); and there is political economy consideration to the problem see: Farhi, Sleet, Werning and Yeltekin (2012),and the negative inheritance tax argument which presence is approved if children's utilities enter in the social welfare, Kaplow(2001). Kotlikoff and Summers (1981) estimate that 70-80 $\%$ of private financial wealth in the US is attributable to intergenerational transfers and only 20-30\% to own life-cycle savings. On the other hand, Modigliani (1988) suggests that these proportions more or less should be reversed. Modigliani,F.,Brumberg ,R.H. (1954), Modigliani, F. (1966),Modigliani(1976) , Modigliani, F. (1986), Modigliani(1988), view states that life cycle wealth accounts for the bulk of wealth (in US). Here key problem is that the definition of life-cycle vs. inherited wealth is not conceptually clean. Previous KotlikoffSummers controversy consisted in the fact that estimates of the share of inherited wealth in aggregate wealth for Modgiliani (1986), Modigliani (1988) definition was $20 \%$ as low, and for Kotlikoff and Summers (1981) was as $80 \%$ high (data were the same). Piketty, T., Postel-Vinay, G., Rosenthal, (2014), give better definition that the individual wealth is a sum of individual earnings minus expenditures (accrued amount) multiplied by compound interest rate. Taxation of inheritances is an old problem, and there are arguments in favor and in opposition of wealth transfers: inheritance taxes are progressive in terms of distributional justice this is a good thing; wealth transfer taxation can be a complement to the income taxation; inheritance taxes may serve to tax capital gains that previously were exempted in many countries; see Poterba,Weisbenner (2001). Inheritance taxes also serve to reduce wealth concentration in the society. On the negative side, wealth taxation as a whole impinges on property rights, inheritance taxation is also fraught with time consistency problems, see Huber (1996), inheritance taxation distorts savings decision also; see Johnson, Diamond, Zodrow (1997). By changing the distribution of wealth, it can affect the growth of capital stock, as well as the functional distribution of income, see Moon, (1989), Ihori (1997). The possible motives for leaving bequest include "altruism": See Barro (1974); "joy of giving" Andreoni, (1989), Benhabib et al., (2011), and the "joy of wealth" Zou, Heng-Fu (1995). In the first Overlapping-generations-Models (OLG) such as that of Diamond (1965), individuals care only about their own lifetime utility and never leave bequests, empirical economist later on (mentioned in this revue) proved that this assumption is wrong. Henry George Theorem(HGT) states $^{30}$ : that with identical individuals, in a city of optimal population size, differential land rents (the aggregate over the city of urban land rent less the opportunity cost of land in nonurban use) equal expenditure on pure local public goods, see Arnott (2004). Whether HGT is a useful guide the optimal size of the city is subject to discussion and jury has not been made yet. Theoretical literature on capital taxation implications for the economic policy would be: "to eliminate all inheritance taxes, property taxes, corporate profits taxes, and individual taxes on capital income and recoup the resulting tax revenue loss with higher labor income or consumption or lump-sum taxes", see Piketty Saez (2012) Atkinson and Stiglitz ${ }^{31}(1976 ; 1980)$ themselves have repeatedly stressed that their famous zero capital tax result relies upon implausibly strong assumptions (most notably the absence of inheritance and the separability of preferences), and has little relevance for practical policy discussions. See also Atkinson and Sandmo (1980) and Stiglitz (1985). Chamley (1986) and Judd (1985) show that the optimal capital income tax would be zero in the long-run, and that this result holds for two reasons: first, because social welfare is measured exclusively from the initial period (or dynasty),second textbook model predicts enormous responses of aggregate capital accumulation to changes in capital tax rates, though this is not supported by the historical data. Capital-output ratios are relatively stable in the long run, in spite of large variations in tax rates, see Piketty (2010).

\section{Bequest taxation model (due to Farhi, Werning (2014))}

\footnotetext{
${ }^{30}$ Henry George Theorem:" states that in any constrained Pareto optimal (which allows for unalterable distortions) and nontrivial (neither indeterminate, completely agglomerated, nor completely dispersed) allocation of population in a spatial economy, the aggregate shadow losses from the increasing returns to scale activities (losses evaluated at social opportunity costs or shadow prices) just equal the aggregate shadow profits from the decreasing returns to scale activities"... see Arnott (2004).

${ }^{31}$ Atkinson and Stiglitz (1976) show that there is no need to supplement the optimal non-linear labor income tax with a capital income tax in a life-cycle model if leisure choice is (weakly) separable from consumption choices and preferences for consumption are homogeneous. If the utility is weakly separable $F(x)=F\left(f^{1}\left(x^{1}\right), \ldots, f^{m}\left(x^{m}\right)\right)$ and $u_{h}\left(c_{1}, \ldots, c_{K}\right)$ and is the same for all individuals then the government should impose only labor tax and consumption tax and not savings tax.
} 
A parent of type $\theta$ has preferences $(1-\theta) \log \left(c_{0}\right)+\theta \log \left(c_{1}-e_{1}\right)$, where $c_{0}$ is consumption of the parent and $c_{1}$ is consumption of the offspring. Taxes (With unrestricted taxes, the most general tax instrument is a nonlinear tax of bequests, a result similar to Mirrlees (1971)) included give :

equation 1

$$
c_{0}+B+T(B)=I(1) c_{1}=e_{1}+R B
$$

where $T$ is a nonlinear tax on bequests. At points where $T$ is differentiable, the marginal tax rate on bequests equals the implicit marginal tax rate on bequests $T^{\prime}\left(\frac{c_{1}(\theta)-I_{1}}{R}\right)=\tau(\theta)$, defined by: ( $1+$ $\tau(\theta))(1-\theta) / c_{0}=R \theta c_{1}$. The following definitions will prove useful. We say that an allocation $\left\{c_{0}(\theta), c_{1}(\theta)\right\}$ is resource feasible if

equation 2

$$
\int\left(c_{0}(\theta)-c_{0}+\frac{c_{1}(\theta)-e_{1}}{R}\right) f(\theta) d \theta \leq 0
$$

An a allocation is IC (incentive compatible if): $(1-\theta) \log \left(c_{0}(\theta)+\theta \log \left(c_{1}(\theta)-e_{1}\right) \geq(1-\right.$ $\theta) \log \left(c_{0}(\hat{\theta})+\theta \log \left(c_{1}(\hat{\theta})-e_{1}\right)\right.$. We continue with the simple tax approach with linear taxes on bequests (together with a lump-sum rebate). An allocation can be implemented with a linear tax on bequests if and only if there exists an income $I$ and an tax rate on bequests $\tau$ such that $: c_{0}(\theta)=(1-\theta) I ; c_{1}(\theta)=e_{1}+\frac{R}{1+\tau} \theta I$. Where $I \int\left(1-\frac{\tau}{1+\tau} \theta\right) f(\theta) d \theta=e_{0}$. If there are no political economy frictions. In this case, taxes are decided in period 0 to maximize a Utilitarian objective. As we will show, in this case, under the unrestricted tax approach, optimal nonlinear taxes on bequests are equal to zero. This also immediately implies that under the simple tax approach, optimal linear taxes on bequests are zero. Maximization problem here is:

equation 3

$$
\max _{\left\{c_{0}(\theta), c_{1}(\theta)\right\}} \int(1-\theta) \log \left(c_{0}(\theta)+\theta \log \left(c_{1}(\theta)-e_{1}\right) f(\theta) d(\theta)\right.
$$

s.t. $\int\left(c_{0}(\theta)-c_{0}+\frac{c_{1}(\theta)-e_{1}}{R}\right) f(\theta) d \theta \leq 0$ (resource feasibility) and $(1-\theta) \log \left(c_{0}(\theta)+\theta \log \left(c_{1}(\theta)-\right.\right.$ $\left.e_{1}\right) \geq(1-\theta) \log \left(c_{0}(\hat{\theta})+\theta \log \left(c_{1}(\hat{\theta})-e_{1}\right)\right.$ or IC (incentive compatibility).

Proposition 1. With no political economy friction, the implicit tax on bequests is $\tau(\theta)=0$. The optimal allocation can be implemented with zero taxes on bequests $T(B)=0$. This result is driven by a feature of our preference specification. The marginal utility of income is equalized across parents at any level of income and interest rate. Indeed, define the indirect utility function

equation 4

$$
V^{p}(I, \hat{R} ; \theta)=\max _{c_{0}, c_{1}}(1-\theta) \log \left(c_{0}(\theta)+\theta \log \left(c_{1}(\theta)-e_{1}\right)\right.
$$

s.t. $c_{0}+\frac{1}{\hat{R}}\left(c_{1}-e_{1}\right)=I$; We have $V_{I}^{p}(I, \hat{R} ; \theta)=V_{I}^{p}(I, \hat{R} ; \theta), \forall \in\left(\theta, \theta^{\prime}, I\right)$. Where $R=e^{r T}$ are the constant rates of return, also children endowment is $e_{1}=\mathcal{G} e_{0}$. The difference between rate of return on capital $r$ and the growth rate of this economy is central to this paper: $R G^{-1}=e^{(r-g) T}$ or $r-g \cdot{ }^{32}$ We now depart from the assumption of no political economy friction. Without political economy friction, taxes are set at $t=0$ when parents make their bequest decisions. There is full commitment, in the sense that any temptation to revise taxes after bequest decisions are made is automatically resisted. Our political economy friction imposes an additional restriction on allocations. We call this new restriction the credibility constraint. To avoid trivial solutions, we assume a reform costs a fraction $\left(1-e^{-k}\right)$ of the available resources where $\kappa \geq 0$, implying the resource constraint(RC): $\int \widetilde{c_{1}}(\theta) f(\theta) d \theta \leq e^{-k} \int c_{1}(\theta) f(\theta) d \theta$. If a reform takes place that criterion: $\int u\left(\tilde{c}_{1}(\theta)\right) f(\theta) d \theta$ is maximized by a constant consumption level: $\widetilde{c_{1}}(\theta)=e^{-k} \int c_{1}(\theta) f(\theta) d \theta$. Comparing the two alternatives, it follows that a reform can be avoided if and only if: $\int \log \left(c_{1}(\theta)\right) f(\theta) d \theta \geq$ $\log \left(\int c_{1}(\theta) f(\theta) d \theta\right)-k$. We start with the simple tax approach. This approach focuses on the dependence of the level of bequest taxes on $R G^{-1}$ : $c_{0}(\theta)=(1-\theta) I ; c_{1}(\theta)=e_{1}+\frac{R}{1+\tau} \theta I$. Consider first the case where the reform cost $\kappa$ is large enough that the

\footnotetext{
${ }^{32}$ This is related with dynamic efficiency $r>g$ otherwise this economy is dynamically inefficient. Though not every equilibrium is inefficient, the efficiency of the equilibrium depends on the Cass-criterion : Feasible path $k_{t}$ is inefficient if and only if $\lim _{t \rightarrow \infty} \sum_{t=0}^{t} p_{t}<\infty$, see Cass(1972). In the terminology of Phelps (1961), the capital stock exceeds the Golden rule level i.e.: $\frac{d k}{d t}>s f(k)-n k$ or $\frac{d k}{d t}>f(k)-c-n k$, or $f(k)>n+p$. Pareto optimal solution when $k^{*}>k^{G}$ (dynamically inefficient economy), can be obtained if the current generation is allowed fast consumption (capital devouring), while future generation to hold their consumption constant, Mankiw;N.G. Summers,L. Zeckhauser R.J.(1989). In the economy without public goods and externalities the competitive equilibrium is Pareto optimal (First fundamental welfare theorem), Arrow (1951), Debreu (1954).Pareto optimality i.e. first fundamental theorem works with either finite number of agents, or finite number of time periods.
} 
the credibility constraint is not binding at the optimum, then the results in Proposition 1 applies and the optimal tax on bequest is zero. Consider now the interesting case where the reform cost $\kappa$ is low enough that the credibility constraint is binding at the optimum. Then I and $\tau$ are entirely pinned down by the resource constraint and the credibility constraint:

$$
\text { equation } 5
$$

$I \int\left(1-\frac{\tau}{1+\tau} \theta\right) f(\theta) d \theta=e_{0} ; \int \log \left(I \frac{R}{1+\tau} \theta+e_{1}\right) f(\theta) d \theta=\log \left(I \frac{R}{1+\tau} \theta \int \theta f(\theta) d \theta+e_{1}\right)-k$

These form a system of two equations in two unknowns $I$ and $\tau$. Defining $\hat{I}=\frac{I}{e_{0}}$, we can then rewrite these conditions as:

equation 6

$\hat{I} \int\left(1-\frac{\tau}{1+\tau} \theta\right) f(\theta) d \theta=1 ;$

$\int \log \left(I \frac{R}{1+\tau} R G^{-1} \hat{I} \theta+1\right) f(\theta) d \theta=\log \left(I \frac{R}{1+\tau} R G^{-1} \hat{I} \int \theta f(\theta) d \theta+1\right)-k$

This formulation makes it clear that the tax rate $\tau$ depends on the gross rate of return on capital $R$ and the gross rate of growth of the economy $G$ only through the sufficient statistic $R G^{-1}$. In fact, the solution is most easily characterized by first defining the following decreasing transformation of $\tau$ as follows:

equation 7

$$
x(\tau)=\frac{1-\frac{\tau}{1+\tau}}{\int\left(1-\frac{\tau}{1+\tau} \theta\right) f(\theta) d \theta^{\prime}}
$$

As well as constant $\hat{x}$ given by : $\int \log (x \hat{\theta}+1) f(\theta) d \theta=\log \left(\hat{x} \int \theta f(\theta)+1\right)-k$. Proposition 2. With political economy frictions, the credibility constraint binds at the optimum if and only if $\hat{x} \leq R G^{-1}$. If the credibility constraint binds at the optimum, then the optimal tax rate $t$ is given by the implicit equation $x(t)=$ $\frac{\hat{x}}{R G^{-1}}$. It is increasing in $R G^{-1}$. The wealth of children is increasing in $R G^{-1}$ (their wealth consists for the bequest they receive from $m$ their parents and income they earn). Inequality arises only from the size of the bequests. The magnitude of these bequests is dependent on the ROC or $R$, and income of the parents. The growth rate of the economy $G$ determines how much the income of the children will be higher of the income of their parents. Temptation or probability to undertake wealth reform increases with $R G^{-1}$ credibility constraint is tied to higher values of $R G^{-1}$.Piketty (2014) hypothesized and theorized that $r-g$ was a crucial determinant of wealth inequality in the economy. Also, tax rate on bequests must increase as $R G^{-1}$ increases. Now in the case of unrestricted taxes, We define $v(\theta)$ to be the utility of a parent of type $\theta$ so that the equation for their utility ${ }^{33}$ is: $v(\theta)=(1-\theta) \log \left(c_{0}(\theta)+\theta \log \left(c_{1}-e_{1}\right)\right.$. Subject to :

equation 8

$$
\begin{gathered}
\int\left[\exp \left(\frac{v(\theta)-\theta \log \left(c_{1}(\theta)-e_{1}\right)}{1-\theta}\right)+\frac{c_{1}(\theta)-e_{1}}{R}\right] f(\theta) d \theta \leq e_{0} \\
\hat{v}(\theta)=\log \left(c_{1}(\theta)-e_{1}\right)-\frac{v(\theta)-\theta \log \left(c_{1}(\theta)-e_{1}\right)}{1-\theta} ; \dot{c}_{1}(\theta) \geq 0 \\
\left.\int \log \left(c_{1}(\theta)\right) f(\theta) d \theta \geq \log \left(\int c_{1}(\theta) f(\theta) d \theta\right)-k\right)
\end{gathered}
$$

It is convenient to perform the following change of variables: $c_{1}(\theta)-e_{1}=\operatorname{Re}_{0} \hat{c}_{1}(\theta), \hat{v}(\theta)=v(\theta)-$ $(1-\theta) \log \left(e_{0}\right)-\theta \log \left(R e_{0}\right), \hat{v}(\theta)=\dot{v}(\theta)-\log (R)$. We can then write the problem as: $\max \int \hat{v}(\theta) f(\theta) d \theta$

s.t.

inequality 1

$$
\begin{array}{r}
\int\left[\exp \left(\frac{\hat{v}(\theta)-\theta \log \left(\hat{c}_{1}(\theta)-e_{1}\right)}{1-\theta}+\hat{c}_{1}(\theta)\right] f(\theta) d \theta \leq 1 ; \hat{v}(\theta)=\frac{\log \left(\hat{c}_{1}(\theta)-\hat{v}(\theta)\right.}{1-\theta} ; \dot{\hat{c}}_{1}(\theta) \geq 0\right. \\
\int \log \left(R G^{-1} \hat{c}_{1}(\theta)+1\right) f(\theta) d \theta \geq \log \left(R G^{-1} \int \hat{c}_{1}(\theta) f(\theta) d \theta+1\right)-k
\end{array}
$$

Since we back out the implicit marginal tax rate:

equation 9

$$
\tau(\theta)=\frac{\theta}{1-\theta} \frac{1}{\hat{c}_{1}(\theta)} \exp \left(\frac{\hat{v}(\theta)-\theta \log \left(\hat{c}_{1}(\theta)\right)}{1-\theta}\right)-1
$$

$\theta$ is a probability type of parent distributed $f(\theta)$. This formulation shows that just as in the simple tax case, $R$ and $G$ influence the optimal tax rate on bequests only through the sufficient statistic $R G^{-1}$. This is an optimal control problem with an integral control constraint. Let $\gamma>0$ be the multiplier on the resource

\footnotetext{
${ }^{33}$ Weil (1987), also argues that dynamic efficiency is necessary condition for the RET (Ricardian equivalence) theorem of Barro (1974) to hold.
} 
constraint, $v \geq 0$ the multiplier on the credibility constraint, and $\mu(\theta)$ the co-state ${ }^{34}$ for $v(\theta)$. Assuming that there is no bunching on an interval around $\theta$, the first-order conditions are:

equation 10

$$
\begin{gathered}
0=\gamma \frac{\theta}{1-\theta} \frac{1}{\hat{c}_{1}(\theta)} \exp \left(\frac{\hat{v}(\theta)-\theta \log \left(\hat{c}_{1}(\theta)\right)}{1-\theta}\right)-\gamma+\frac{\mu(\theta)}{f(\theta)} \frac{1}{1-\theta} \frac{1}{\hat{c}_{1}(\theta)} \\
+v R G^{-1}\left[\frac{1}{R G^{-1} \hat{c}_{1}(\theta)+1}-\frac{1}{\int R G^{-1} \hat{c}_{1}(\theta) f(\theta) d \theta+1}\right] \\
\dot{\mu}(\theta)=-f(\theta)+\gamma \frac{1}{1-\theta} \exp \left(\frac{\hat{v}(\theta)-\theta \log \left(\hat{c}_{1}(\theta)\right)}{1-\theta}\right) f(\theta) \\
\mu(\underline{\theta})=\mu(\bar{\theta})=0
\end{gathered}
$$

Proposition 3. Assume that the reform $\operatorname{cost} \kappa$ is low enough that the credibility constraint binds at the optimum. If there is no bunching on an interval around $\theta$. The optimal marginal tax rate on bequests is given by the following formula

equation 11

$$
\tau(\theta)=-\frac{\mu(\theta)}{\gamma f(\theta)} \frac{1}{1-\theta} \frac{1}{\hat{c}_{1}(\theta)}+\frac{v}{\gamma} R G^{-1}\left[\frac{1}{\int R G^{-1} \hat{c}_{1}(\theta) f(\theta) d \theta+1}-\frac{1}{R G^{-1} \hat{c}_{1}(\theta)+1}\right]
$$

where $\mu(\underline{\theta})=\mu(\bar{\theta})=0$. If there is no bunching at the extremes, then $\tau(\underline{\theta})<0<\tau(\bar{\theta})$.

\section{Estate taxation model (Stiglitz,1978)}

Stiglitz, (1978) argues that estate tax may not increase equality of income due to reduction of savings and capital accumulation that in the long run will to lower $K / L$, and if $\sigma<1$ this will lead to an increase in the share of capital ${ }^{35}$. And the rationale is that since income from capital is more unequally distributed than is labor income, the increase in the proportion of income accruing from capital may increase overall inequality. Function of bequest is : $B=s Y(t)-a+B(t-1)$, $\mathrm{s}-$ marginal savings rate; $a>0$ - intercept of the consumption function; $\mathcal{Y}_{i}=w_{i} L_{i}+r C_{i}$-lifetime consumption function, ; $C_{i}$-is the amount of inherited capital of the family; $r$-is the interest rate, $L_{i}$-number of family members that are wage earners, $n$-rate of the increase of the family size, $y_{i}$-per capita income in the family, $c_{i}$-capital per capita in the family, dynamic of capital accumulation in the family is $\dot{c}_{I}=s w_{i}-a+(s r-n) c_{i}$. In equilibrium $: \dot{c}_{l}=\frac{s w_{i}-a}{n-s r} . \mathrm{CV}$ or coefficient of variation of wealth is: $\quad \gamma_{c}^{2}=\frac{E\left(c_{i}-\bar{c}\right)^{2}}{\bar{c}^{2}}=\frac{s^{2} \sigma_{w}^{2}}{(s \bar{w}-a)^{2}} \cdot \sigma_{w}^{2}$ - is the wage variance; $\bar{w}$ - is the average wage in the household. If $a=0 ; \gamma_{c}=$ $\gamma_{w}$ dispersion of wages and capital is identical and if $a>0 ; \gamma_{c}>\gamma_{w}$ capital is more equally distributed than the wages. If $p_{i}$ is the proportion in the $\mathrm{i}$-th group then: $k \equiv \bar{c} \equiv \sum p_{i} c_{i}=\frac{s \bar{w}-a}{n-s r} ; y_{i}=w_{i}+r c_{i}=\frac{n w_{i}-a r}{n-s r}$ and so: $\gamma_{y}^{2}=\frac{n^{2}}{(n-s r)^{2}} \frac{\sigma_{w}^{2}}{\bar{y}^{2}}=\left(\frac{n}{n-r}\right)^{2} \gamma_{w}^{2} \alpha^{2}=\left[\frac{(s y-a)}{s w-a} \alpha\right]^{2} \gamma_{w}^{2}=\gamma_{w}^{2} ; a=0 ; \alpha$-is the labor share .Now with the imposition of the bequest tax $\tau: \dot{c}_{l}=\left(s w-a+s r c_{i}+s \tau k\right)-(n+\tau) c_{i} ; \dot{k}=s \bar{w}-a+s(r+\tau) k-(n+\tau) k$. On the long run: $c_{i}=\frac{s w_{i}-a+s \tau k}{n+\tau-s r} ; k=\frac{s \bar{w}-a+s \tau k}{n-s r+\tau(1-s)}$. Or:

equation 12

$k[n+\tau(1-s)]=s y(k)-a ; y \equiv w+r k=f(k) ; f^{\prime}>0^{\prime} ; f^{\prime \prime}<0 ; \frac{d k}{d \tau_{\mid s}}=\frac{(1-s) k}{s y^{\prime}-\left(\frac{s y}{k}\right)+\left(\frac{a}{k}\right)}=-\frac{(1-s) k^{2}}{s \bar{w}-a}$

$\mathrm{CV}$ or coefficient of variation of capital and wages with taxation of bequests $: \gamma_{c}^{2}=\frac{s^{2} \bar{w}^{2} \gamma_{w}^{2}}{(s \bar{w}-a+s \tau k)^{2}}$ $\frac{a}{s}\left(\frac{1}{w}-\frac{1}{\widehat{w}}\right), t^{*}$ - minimizes wealth inequality $\widehat{w}$ is the value of $w$ at $\tau=0$. Now the coefficient of variation of wealth increases or decreases $\gtrless$ :

equation 13

$\frac{d \gamma_{c}}{d \tau} \gtrless 0 ; \frac{d\left[\frac{\tau k}{w}-\frac{a}{s \bar{w}}\right]}{d \tau} \lessgtr 0 ; \frac{d\left[\frac{\tau k}{w}-\frac{a}{s \bar{w}}\right]}{d \tau}=\frac{k}{\bar{w}}-\frac{(1-s) k^{2}}{s \bar{w}-a}\left[\frac{\tau}{\bar{w}}+\left(\frac{\tau k}{\bar{w}}-\frac{a}{s \bar{w}}\right) \frac{k f^{\prime \prime}}{\bar{w}}\right]=\frac{k}{\bar{w}}\left(1-\frac{1-s}{n+\tau(1-s)-s r}[\tau-\right.$

$\left.\left.\left(\tau k-\frac{a}{s}\right) \frac{r}{f \sigma}\right]\right)>0$

${ }^{34}$ Function of time rather than constants. Or perhaps $\dot{\mu}^{T}(t)=-\frac{\partial \mathcal{L}}{\partial \theta}$.

${ }^{35} \sigma=\frac{d \ln \left(\frac{K}{L}\right)}{\operatorname{dln}\left(\frac{F_{L}}{F_{K}}\right)}$ where $F_{L}=\frac{\partial F}{\partial L}$ and $F_{K}=\frac{\partial F}{\partial K}$. This comes from normalized CES production function in the form of:

$Y_{i t}=F\left(K_{i t}, L_{i t}, \Gamma_{i t}^{h}, \Gamma_{i t}^{\ell}\right)=Y_{i 0}\left[\pi_{i 0}\left(\Gamma_{i t}^{k} \frac{K_{i t}}{K_{i 0}}\right)^{\frac{\sigma-1}{\sigma}}+\left(1-\pi_{i 0}\right)\left(\Gamma_{i t}^{h} \frac{L_{i t}}{L_{i 0}}\right)^{\frac{\sigma-1}{\sigma}}\right]^{\frac{\sigma-1}{\sigma}}$,see Mućk (2017). 
Elasticity of substitution is $\sigma=-f^{\prime}\left(f-k f^{\prime}\right) / f f^{\prime \prime} k$ or $r<\frac{[\tau(1-\alpha) \sigma]+\left(\frac{n}{1-s}\right)}{\left(\frac{a}{s f \sigma}\right)+\frac{s}{1-s}}$ and $y_{i}=w_{i}=r c_{i}=$ $\frac{w_{i}(n+t)-r(a-s \tau k)}{n+\tau-s r}$, where: $\gamma_{y}^{2}=\frac{\bar{w}(n+t)-r(a-s \tau k)}{n+\tau-s r} ; \gamma_{y}^{2}=\gamma_{w}^{2}\left[\frac{\bar{w}_{i}(n+\tau)}{\bar{w}_{i}(n+\tau)-r(a-s \tau k)^{2}}\right]^{2}$ Taxes on bequest increase equality if following holds:

$$
\begin{aligned}
& \begin{array}{c}
\text { equation } 14 \\
d\left\{\frac{[s \tau(1-\alpha)]}{[(n+\tau) \alpha]}-\frac{a r}{[\bar{w}(n+\tau)]}\right\} \\
d \tau
\end{array} \\
& \quad=\frac{\left[\frac{s n(1-\alpha)}{\alpha}+\frac{a r}{\bar{w}}\right]}{(n+\tau)^{2}}-\frac{1}{n-s r+\tau(1-s)} \cdot \frac{1-\alpha}{\alpha} \cdot \frac{1-s}{n+\tau}\left[\frac{a}{k}+\left(1-\frac{1}{\sigma}\right)\left(s \tau-\frac{a}{k}\right)\right]>0
\end{aligned}
$$

If $s$ changes for $k$ to remain constant then folowng applies: $\frac{d \gamma_{y}}{d \tau} \gtrless-\frac{d\left[\frac{[\tau \tau(1-\alpha)]}{[(n+\tau) \alpha]}-\frac{a r}{[\bar{w}(n+\tau)]}\right\}}{d \tau \mid k} \lessgtr 0$ and :

equation 15

$$
\frac{d\left\{\frac{[s \tau(1-\alpha)]}{[(n+\tau) \alpha]}-\frac{a r}{[\bar{w}(n+\tau)]}\right\}}{d \tau_{\mid k}}=\frac{n s(1-\alpha)}{(n+\tau)^{2} \alpha}+\frac{a r}{\bar{w}(n+\tau)^{2}}+\frac{\tau(1-\alpha)}{(n+\tau) \alpha} \frac{d s}{d \tau_{\mid k}}>0
$$

So the balanced growth effects with $k$ constant, mean that inheritance taxation does reduce inequality. But if the model is two-class model with income distribution the result on bequest taxes is somehwat different from previous. Capitalists save more $s_{c}$ than workers $s_{w} s_{c}>s_{w}$, and differential equations for their capital are: $\dot{k}_{c}=s_{c} r k_{c}-(n+\tau) k_{c} ; \dot{k}_{w}=s_{w}\left(w+r k_{w}+k \tau\right)-(n+\tau) k_{w}$., steady-state interest rate is $: r=$ $\frac{n+\tau}{s_{c}}$.Steady state workers capital in ratio with total capital is:

equation 16

$$
\begin{aligned}
& {\left[s_{w} r-(n+\tau)\right] \frac{k_{W}}{k}+\frac{s_{w} \alpha r}{1-\alpha}+s_{w} \tau=\left(\frac{s_{W}}{s_{c}}-1\right)(n+\tau) \frac{k_{w}}{k}+\frac{s_{W} \alpha(n+\tau)}{s_{c}(1-\alpha)}+s_{w} \tau-0 ; \frac{k_{W}}{k}=\frac{\left(\frac{s_{w} s_{c} \tau}{n+\tau}+\frac{s_{W} \alpha}{1-\alpha}\right)}{s_{c}-s_{W}} ; } \\
\frac{\frac{d k_{w}}{k}}{d \tau_{\mid \tau=0}}= & \left(\frac{\sigma-1}{1-\alpha}+s_{c}\right) \frac{s_{W}}{n\left(s_{c}-s_{W}\right)}<0
\end{aligned}
$$

If $\sigma<1-(1-\alpha) s_{c}$, for low values of the elasticity of substitution proportion of the capital in ownership of workers will decrease as a result of the taxation of bequest, but the capitalist share will increase.

equation 17

inequality 2

$$
\frac{r\left(k-k_{w}\right)}{f}=(1-\alpha)\left(1-\frac{k_{w}}{k}\right)
$$

$$
\left.\frac{d\left\{1-\alpha-\frac{\left[(1-\alpha) s_{W} s_{c} \tau\right]}{\left[(n+\tau)\left(s_{c}-s_{W}\right)\right]}-\frac{s_{W} \alpha}{s_{c}-s_{W}}\right\}}{d \tau}\right|_{\tau=0}=\left[-\alpha^{\prime} \frac{d k}{d \tau}-\frac{(1-\alpha) s_{W}}{n}\right] \frac{s_{c}}{\left(s_{c}-s_{W}\right)}=\left[(1-\sigma)-s_{w}\right] \frac{(1-\alpha) s_{c}}{\left(s_{c}-s_{W}\right) n}>0 ; \sigma<1-s_{w}
$$

$f$ is the per capita production function. Bequest function $B(w, c)$ is monotinicaly increasing $B_{w} \geq$ $0, B_{c} \geq 0$ but marginal propensity for bequest as the capital increases or as wages increase is lee than 1 i.e $B_{w}<$ $1 ; B_{c}<1$. Now, consumption function si given as: $C=w+c-B(w, c)$. Household wealth accumulation follows:

$$
\begin{aligned}
& \text { equation } 18 \\
& \dot{c}=B\left(w_{\max } \cdot c\right)-c-n c ; w=w_{\max } ; c=c_{\max } ; C=w-n c<w_{\max } \\
& \frac{\partial C}{\partial w}=1-B_{w}>0 ; \frac{\partial C}{\partial c}=1-B_{c}>0 \quad C(w, c)<C\left(w_{\max }, c_{\max }\right)
\end{aligned}
$$

More capable individuals save more (spend less) from their incomes,i.e. the income that they will consume if the bequests were not permitted. Less capapble individuals spend their incomes if the inheritances are not allowed.

\section{A case for progressive estate taxation (Farhi, Werning (2010))}

This is a model with altruistic parents and heterogenous productivity. The authors first propose progressive estate tax, so that altruistic parents leaving higher bequest face lower net return on bequests.Second, marginal tax rate should be negative so that all parents face a marginal subsidy on bequests. If one takes the expected utility for parents as the social welfare objective, then Atkinson ; Stiglitz's (1976) uniform taxation result applies ${ }^{36}$. In this economy at the beginning of period $t=0$, parents first learn their productivity $\theta_{0}$, and

\footnotetext{
${ }^{36}$ This implies that parents' intertemporal utility choice should not be distorted. When no direct weight is placed on the welfare of children, labor income should be taxed non-linearly, but bequests should remain untaxed.
} 
then produce $n_{0}$ efficiency units of labor. This requires $\frac{n_{0}}{\theta_{0}}$ units of work effort. The utility of a parent with productivity $\theta_{0}$ is given by he following :

equation 19

$$
v_{0}\left(\theta_{0}\right)=u\left(c_{0}\left(\theta_{0}\right)\right)-h\left(\frac{n_{0}\left(\theta_{0}\right)}{\theta_{0}}\right)+\beta v_{1}\left(\theta_{0}\right)
$$

With $\beta<1$; childs utility is $v_{1}\left(\theta_{0}\right)=u\left(c_{1}\left(\theta_{0}\right), u(c)\right.$ is increasing and concave, differentiable and satisfies Inada conditions, $u^{\prime}(0)=\infty ; u^{\prime}(\infty)=0$; the disutility function $h(n)$ is increasing , convex differentiable.So now, $v_{0}(\theta)=u\left(c_{0}\right)+\beta u\left(c_{1}\right)-h\left(\frac{n_{0}\left(\theta_{0}\right)}{\theta_{0}}\right)$. There is endowment $e_{0}$ in the period $t=0$; and endowment of $e_{1}$ in the period $t=1$. Goods are transferred between periods $t=0 ; t=1$ with a linear savings technology with ROR $R>0$.An allocation is resource feasible if :

inequality 3

$$
K_{1}+\int_{0}^{+\infty} c_{0}\left(\theta_{0}\right) d F\left(\theta_{0}\right) \leq e_{0}+\int_{0}^{\infty} n_{0}\left(\theta_{0}\right) d F\left(\theta_{0}\right) ; \int_{0}^{+\infty} c_{1}\left(\theta_{0}\right) d F\left(\theta_{0}\right) \leq e_{1}+R K_{1}
$$

where in previous $K_{1}$ is capital. Resource constraint is given as: $\int_{0}^{+\infty} c_{0}\left(\theta_{0}\right) d F\left(\theta_{0}\right)+$ $\frac{1}{R} \int_{0}^{+\infty} c_{1}\left(\theta_{0}\right) d F\left(\theta_{0}\right) \leq e_{o}+\frac{1}{R} e_{1}+\int_{0}^{\infty} n_{0}\left(\theta_{0}\right) d F\left(\theta_{0}\right)$. An allocation is IC (incentive compatible) and truthfully revelational if: $u\left(c_{0}\left(\theta_{0}\right)\right)+\beta u\left(c_{1}\left(\theta_{0}\right)\right)-h\left(\frac{n_{0}\left(\theta_{0}\right)}{\theta_{0}}\right) \geq u\left(c_{0}\left(\theta_{0}^{\prime}\right)\right)+\beta u\left(c_{1}\left(\theta^{\prime}{ }_{0}\right)\right)-h\left(\frac{n_{0}\left(\theta_{0}^{\prime}\right)}{\theta_{0}}\right), \forall \theta_{0} ; \theta_{0}^{\prime}$. Two utilitarian welfare measures are: $V_{0} \equiv \int_{0}^{\infty} v_{0}\left(\theta_{0}\right) d F\left(\theta_{0}\right) ; V_{1} \equiv \int_{0}^{\infty} v_{1}\left(\theta_{0}\right) d F\left(\theta_{0}\right) ;$ and $V_{0} \equiv \int_{0}^{\infty}\left(u\left(c_{0}\left(\theta_{0}\right)-\right.\right.$ $h\left(y\left(\frac{\theta_{0}}{\theta_{0}}\right)\right) d F\left(\theta_{0}\right)+\beta V_{1}$.Implicit estate tax rate is defined as:

equation 20

$$
(1+\tau(\theta)) u^{\prime}\left(c_{0}\left(\theta_{0}\right)\right) \equiv \beta R u^{\prime}\left(c_{1}\left(\theta_{0}\right)\right)
$$

Implicit inheritance tax $\hat{\tau}\left(\theta_{0}\right)$ is:

equation 21

$$
u^{\prime}\left(c_{0}\left(\theta_{0}\right)\right) \equiv \beta R\left(1-\hat{\tau}\left(\theta_{0}\right)\right) u^{\prime}\left(c_{1}\left(\theta_{0}\right)\right)
$$

Where tax wedges: $\hat{\tau}\left(\theta_{0}\right)=\frac{\tau\left(\theta_{0}\right)}{1+\tau\left(\theta_{0}\right)}$ and $\tau\left(\theta_{0}\right)=\frac{\hat{\tau}\left(\theta_{0}\right)}{1+\hat{\tau}\left(\theta_{0}\right)}$. The Euler equation $u^{\prime}\left(c_{0}\right)=\beta R u^{\prime}\left(c_{1}\right)$ implies that dynastic consumption is smoothed. If the utility function is CRRA $u(c)=\frac{c^{1-\sigma}}{1-\sigma}$ or $c_{1}\left(\theta_{0}\right)=(\beta R)^{\frac{1}{\sigma}} c_{0}\left(\theta_{0}\right)$, or equivalently $\log c_{1}\left(\theta_{0}\right)-\log c_{0}\left(\theta_{0}\right)=\frac{1}{\sigma} \log (\beta R)$. Proposition 4.Suppose $V_{1}>V_{1}^{*}$ and that the optimal allocation has strictly positive consumption. The implicit estate tax is strictly negative and increasing in the parent's productivity $\theta$ i.e. looks like this:

equation 22

$$
\tau\left(\theta_{0}\right)=-R \frac{v}{\mu} u^{\prime}\left(c_{1}\left(\theta_{0}\right)\right)
$$

Implicit inheritance $\operatorname{tax} \hat{\tau}\left(\theta_{0}\right)$ is:

equation 23

$$
\hat{\tau}\left(\theta_{0}\right)=\frac{\tau\left(\theta_{0}\right)}{1+\tau\left(\theta_{0}\right)}=-\frac{1}{\beta} \frac{v}{\mu} u^{\prime}\left(c_{0}\left(\theta_{0}\right)\right)
$$

$\mu$ is a multiplier and comes from the Lagrangian:

equation 24

$$
\mathcal{L} \equiv \int_{0}^{\infty}\left[v_{0}\left(\theta_{0}\right)+v v_{1}\left(\theta_{0}\right)\right] d F\left(\theta_{0}\right)-\mu \int_{0}^{\infty}\left[c_{0}\left(\theta_{0}\right)+\frac{c_{1}\left(\theta_{0}\right)}{R}-n_{0}\left(\theta_{0}\right)\right] d F\left(\theta_{0}\right)
$$

One perturbation to be considered is: $c_{0}^{\varepsilon}\left(\theta_{0}\right)=c_{0}\left(\theta_{0}\right)+\varepsilon$ and now $u\left(c_{0}^{\varepsilon}\left(\theta_{0}\right)\right)+\beta u\left(c_{1}\left(\theta_{0}\right)\right)$. FOC or partial derivative $\frac{\partial \mathcal{L}}{\partial \varepsilon}=0$ which yields:

equation 25

$$
\frac{\beta R}{u^{\prime}\left(c_{0}\left(\theta_{0}\right)\right)}=\frac{1}{u^{\prime}\left(c_{1}\left(\theta_{0}\right)\right)}-R \frac{v}{\mu}
$$

Or by rearranging previous we get : $u^{\prime}\left(c_{0}\left(\theta_{0}\right)\right)=\beta R\left(1-\frac{1}{\beta} \frac{v}{\mu} u^{\prime}\left(c_{0}\left(\theta_{0}\right)\right)\right) u^{\prime}\left(c_{1}\left(\theta_{0}\right)\right)$. An allocation is said to be implemented by a non-linear labor income $\operatorname{tax} T^{y}\left(n_{0}\right)$ and estate $\operatorname{tax} T^{b}(b)$ if, for all $\theta_{0}$, $\left(c_{0}\left(\theta_{0}\right) ; c_{1}\left(\theta_{0}\right) ; n_{0}\left(\theta_{0}\right)\right)$ solves for the following or maximizes the following: 
inequality 4

$$
\max _{c_{0}, c_{1}, n_{0}}\left(u\left(c_{0}\right)+\beta u\left(c_{1}\right)-h\left(\frac{n_{0}}{\theta_{0}}\right)\right)
$$

s.t. $\quad c_{0}+b \leq e_{0}+n_{0}+T^{b}(b)-T^{y}\left(n_{0}\right), c_{1} \leq e_{1}+R b \quad$.Now FOC gives: $\left(1+T^{\prime b}(b)\right) u^{\prime}\left(c_{0}\right)=$ $\beta R u^{\prime}\left(c_{1}\right)$, and by using budget constraint: $c_{1}=e_{1}+R b$, we obtain now:

equation 26

$$
T^{b^{\prime}}(b)=-R \frac{v}{\mu} u^{\prime}\left(e_{1}+R b\right)
$$

It is also possible to implement inheritance taxes paid by the child, and this tax allocation is implementable by non-inear income and inheritance taxes $\hat{T}^{y}\left(n_{0}\right)$ and $\hat{T}^{b}(R b)$ if $\left(c_{0}\left(\theta_{0}\right) ; c_{1}\left(\theta_{0}\right) ; n_{0}\left(\theta_{0}\right)\right)$ maximizes the utility for a parent with productivity $\theta_{0}: \max _{c_{0}, c_{1}, n_{0}}\left(u\left(c_{0}\right)+\beta u\left(c_{1}\right)-\right.$ $\left.h\left(\frac{n_{0}}{\theta_{0}}\right)\right)$ s.t. $\quad c_{0}+b \leq e_{0}+n_{0}+\widehat{T}^{y}\left(n_{0}\right), c_{1} \leq e_{1}+R b-\widehat{T}^{b}(R b)$.FOC now is: $u^{\prime}\left(c_{0}\left(\theta_{0}\right)\right)=\beta R(1-$ $\left.\frac{1}{\beta} \widehat{T}^{\prime}(R b)\right) u^{\prime}\left(c_{1}\right)$. Now the differential tax equation is :

equation 27

$$
\frac{\widehat{T}^{b^{\prime}}(R b)}{1-\widehat{T}^{b^{\prime}}(R b)}=-R \frac{v}{\mu} u^{\prime}\left(e_{1}+R b-\widehat{T}^{b}(R b)\right)
$$

With any arbitrary value $T^{b}(0)$.With this inheritance tax the budget set of affordable $c_{0}, c_{1}, n_{0}$ is identical to the one with proposed estate tax implementation. Another implementation might be with non-linear income tax and a regressive consumption tax $T^{c}\left(c_{1}\right)$ in the second period. Extension of estate tax with the welfare functions is given as:

equation 28

$$
\tau\left(\theta_{0}\right)=-R \frac{v}{\mu} \widehat{W}_{1}^{\prime}\left(u\left(c_{1}\left(\theta_{0}\right)\right)\right) u^{\prime}\left(c_{1}\left(\theta_{0}\right)\right)
$$

Where $\widehat{W}_{0}(v)=v$ and $\widehat{W}_{1}(v)=v$; otherwise: for parents $W_{0}=\int_{0}^{\infty} \widehat{W}_{0}\left(v_{0}\left(\theta_{0}\right), \theta_{0}\right) d F\left(\theta_{0}\right)$ and for children $W_{1}=\int_{0}^{\infty} \widehat{W}_{1}\left(1\left(\theta_{0}\right)\right) d F\left(\theta_{0}\right)$. Since $\widehat{W}_{1}$ is increasing and concave it follows that $\tau\left(\theta_{0}\right)$ is negative and increasing with $\theta$ so the estate tax is negative and progressive. For a given $\frac{v}{\mu}$ more concave welfare functions imply more progressive tax schedules. In most countries' debt is not inheritable so now we won't impose debt constraints. And the welfare criterion is Rawlsian instead of utilitarian. With Rawlsian welfare criterion, the planning problem $W_{0}$ maximizes subject to RC and IC. Resource constraint is given as: $\int_{0}^{+\infty} c_{0}\left(\theta_{0}\right) d F\left(\theta_{0}\right)+$ $\frac{1}{R} \int_{0}^{+\infty} c_{1}\left(\theta_{0}\right) d F\left(\theta_{0}\right) \leq e_{o}+\frac{1}{R} e_{1}+\int_{0}^{\infty} n_{0}\left(\theta_{0}\right) d F\left(\theta_{0}\right)$. An allocation is IC (incentive compatible) and truthfully revelational if: $u\left(c_{0}\left(\theta_{0}\right)\right)+\beta u\left(c_{1}\left(\theta_{0}\right)\right)-h\left(\frac{n_{0}\left(\theta_{0}\right)}{\theta_{0}}\right) \geq u\left(c_{0}\left(\theta_{0}^{\prime}\right)\right)+\beta u\left(c_{1}\left(\theta^{\prime}{ }_{0}\right)\right)-h\left(\frac{n_{0}\left(\theta_{0}^{\prime}\right)}{\theta_{0}}\right), \forall \theta_{0} ; \theta_{0}^{\prime}$.Also another restriction to the previous problem is $: u_{1}\left(\theta_{0}\right) \geq \underline{u}_{1} ; \forall \theta_{0} ; \underline{u}_{1}$ parametrizes min.utility level for children, and consumption level $\underline{c}_{1}=u^{-1}\left(\underline{u}_{1}\right)$.And now the tax rate for $\theta_{0}<\underline{\theta}_{0}$ and $c_{1}\left(\theta_{0}\right)=\underline{c}_{1}$ we have:

equation 29

$$
\tau\left(\theta_{0}\right)=\beta R \frac{u^{\prime}\left(\underline{\left.\underline{c_{1}}\right)}\right.}{u^{\prime}\left(c_{0}\left(\theta_{0}\right)\right)}-1
$$

Since $c_{0}\left(\theta_{0}\right)$ is non-decreasing and positive it follows that $\tau\left(\theta_{0}\right)$ is non-decreasing and negative. Borrowing constraints with the agents of type $\theta_{0}$ are: $c_{0}+b \leq e_{0}+n_{0}+\widehat{T}^{y}\left(n_{0}\right), c_{1} \leq e_{1}+R b-\hat{T}_{1}^{y}$.Under these conditions children pay lump-sum taxes $: \hat{T}_{1}^{y} \equiv e_{1}-\underline{c}_{1}$, so when $b=0$ they consume $\underline{c}_{1}$. Proposition 4 . Suppose now that the welfare function for the children's generation is Rawlsian. Then the optimal allocation can be implemented with an income tax for parents, $T^{y}$, a lump-sum tax for the child, $\hat{T}_{1}^{y}$, and a no-debt constraint, $b \geq 0$.The Rawlsian case and no-debt constraint are limits of a: $\lim _{k \rightarrow \infty} \lim _{u_{1} \downarrow \underline{u}_{1}} \widehat{W}_{1, k}^{\prime}\left(u_{1}\right)=0 ; \lim _{k \rightarrow \infty} \lim _{u_{1} \uparrow \underline{u}_{1}} \widehat{W}_{1, k}^{\prime}\left(u_{1}\right)=$ 0 ; where $\widehat{W}_{1, k}^{\prime}$ are differentiable welfare functions. Now in the model educational subsidies are introduced ${ }^{37}$.Now let $x$ are investments, and $H(x)$ is the acquired human capital where $H$ is concave increasing and differentiable with Inada conditions $H^{\prime}(0)=\infty$ and $H^{\prime}(\infty)=0$. RC constraint (resource constraint) now becomes:

\footnotetext{
${ }^{37}$ In this model parents previously made bequests as the only type of intergenerational transfers, but educational investments that parents do for their children are also an important part of giving by parents.
} 
equation 30

$$
\left.\left.\int_{0}^{\infty}\left(c_{0}\left(\theta_{0}\right)+\frac{c_{1}\left(\theta_{0}\right)}{R}\right) d F\left(\theta_{0}\right) \leq e_{0}+\frac{e_{1}}{R}+\int_{0}^{\infty}\left(n_{0}\left(\theta_{0}\right)\right)\right)+\frac{H\left(x\left(\theta_{0}\right)\right)}{R}-x\left(\theta_{0}\right)\right) d F\left(\theta_{0}\right)
$$

Preferences here are: $v_{0}(\theta)=u\left(c_{0}\left(\theta_{0}\right)\right)-h\left(\frac{n_{0}\left(\theta_{0}\right)}{\theta_{0}}\right)+\beta v_{1}\left(\theta_{0}\right), v_{1}\left(\theta_{0}\right)=U\left(c_{1}\left(\theta_{0}\right), H\left(x\left(\theta_{0}\right)\right)\right)$. The formula for the implicit estate tax is unafected:

$$
\tau\left(\theta_{0}\right)=-R \frac{v}{\mu} U_{c_{1}}\left(c_{1}\left(\theta_{0}\right), H\left(\theta_{0}\right)\right)
$$

So now three taxes are implemented: a non-linear income tax schedule $T^{y}$, a non-linear estate $\operatorname{tax} T^{b}$ and non-linear human capital tax $T^{x}$. The parent maximizes : $u\left(c_{0}\right)-h\left(\frac{n_{0}}{\theta_{0}}\right)+\beta U\left(c_{1}, H(x)\right)$; s.t. $c_{0}+b+x \leq$ $e_{0}+n_{0}+T^{y}\left(n_{0}\right)-T^{b}(b)-T^{x}(x), c_{1} \leq e_{1}+R b-H(x)$. Now required equalizing between marginal tax rates on estate and marginal tax rates on human capital gives the following:

equation 31

$$
\left.T^{x^{\prime}}\left(x\left(\theta_{0}\right)\right)\right)=T^{b^{\prime}}\left(\frac{c_{1}(\theta)-e_{1}-H(x(\theta))}{R}\right)=\tau(\theta)
$$

This model Farhi, Werning (2010), augment to introduce fertility also. Preferences in this model now are as in Becker,Barro (1988).In this model $m$ is the variable for the number of children in the household,joint distribution of fertility ad productivity is $\hat{F}\left(\theta_{0}, m\right)$, utility of the parent $\left(\theta_{0}, m\right)$ is given as: $u\left(c_{0}\right)-h\left(\frac{n_{0}}{\theta_{0}}\right)+$ $\sum_{j=1}^{m} \beta_{m} u\left(c_{1, j}\right)$, where $\beta_{m}$ is the altruism factor. The welfare measures are : $V_{0}=$ $\int_{0}^{\infty} v_{0}\left(\theta_{0}, m\right) d \hat{F}\left(\theta_{0}, m\right) ; \quad: \quad V_{1}=\int_{0}^{\infty} v_{1}\left(\theta_{0}, m\right) m d \hat{F}\left(\theta_{0}, m\right) \quad, \quad$ with $\quad v_{0}\left(\theta_{0}\right)=u\left(c_{0}\left(\theta_{0} ; m\right)\right)+$ $m \beta_{m} u\left(c_{1}\left(\theta_{0} ; m\right)\right)-h\left(n_{0}\left(\theta_{0}\right)=\theta_{0}\right) ; v_{1}\left(\theta_{0} ; m\right)=u\left(c_{1}\left(\theta_{0} ; m\right)\right)$. Resource constraint (RC) is given as: $\int_{0}^{+\infty} c_{0}\left(\theta_{0}, m\right)+m\left(k+\frac{1}{R} c_{1}\left(\theta_{0}, m\right)\right) d \hat{F}\left(\theta_{0}, m\right) \leq e_{o}+\frac{1}{R} e_{1}+\int_{0}^{\infty} n_{0}\left(\theta_{0}, m\right) d \hat{F}\left(\theta_{0}, m\right)$; IC (constraints) are : $u\left(c_{0}\left(\theta_{0}, m\right)\right)+m \beta_{m} u\left(c_{1}\left(\theta_{0}, m\right)\right)-h\left(\frac{n_{0}\left(\theta_{0}, m\right)}{\theta_{0}}\right) \geq u\left(c_{0}\left(\theta_{0}^{\prime}, m\right)\right)+m \beta_{m} u\left(c_{1}\left(\theta^{\prime}{ }_{0}, m\right)\right)-$ $h\left(\frac{n_{0}\left(\theta_{0}^{\prime}, m\right)}{\theta_{0}}\right), \forall \theta_{0} ; \theta_{0}^{\prime}$.The implicit tax rate is given as folowing:

equation 32

$$
\tau\left(\theta_{0}, m\right)=-R \frac{v}{\mu} u^{\prime}\left(c_{1},\left(\theta_{0}, m\right)\right)
$$

Now the model with endogenous fertility choice such as in Becker,Barro (1988) had been implemented, the difference between exogenous fertility model and endogenous fertility model is the IC constraint that in endogenous fertility model becomes:

inequality 5

$$
\begin{aligned}
u\left(c_{0}\left(\theta_{0}\right)\right)+m\left(\theta_{0}\right) \beta_{m\left(\theta_{0}\right)} u\left(c_{1}\left(\theta_{0}\right)\right)-h\left(\frac{n_{0}\left(\theta_{0}\right)}{\theta_{0}}\right) \\
\geq u\left(c_{0}\left(\theta_{0}^{\prime}\right)\right)+m\left(\theta_{0}^{\prime}\right) \beta_{m_{\theta_{0}^{\prime}}} u\left(c_{1}\left(\theta^{\prime}{ }_{0}\right)\right)-h\left(\frac{n_{0}\left(\theta_{0}^{\prime}\right)}{\theta_{0}}\right), \forall \theta_{0} ; \theta_{0}^{\prime}
\end{aligned}
$$

Marginal tax rates in this model should be negative and progressive. This requires additional constraints such as: $u^{\prime}\left(c_{0},\left(\theta_{0}\right)\right) \leq \beta R u^{\prime}\left(c_{1}\left(\theta_{0}\right)\right) ; \forall \theta_{0}$. Implicit marginal estate tax rate becomes:

equation 33

$$
\frac{\tau\left(\theta_{0}\right)}{1+\tau\left(\theta_{0}\right)}=\max \left\{0,-\frac{1}{\beta} \frac{v}{\mu} u^{\prime}\left(c_{0}, \theta_{0}\right)\right\}
$$

Now if $K$ goods are invested in $t=0$, then $G\left(K_{1}\right)$ goods are available in $t=1$, where $G$ is concave and twice differentiable. Resource constraint now will be:

inequality 6

$$
\int_{0}^{+\infty} c_{0}\left(\theta_{0}\right) d F\left(\theta_{0}\right) \leq e_{1}+G\left(e_{0}+\int_{0}^{\infty} n_{0}\left(\theta_{0}\right) d F\left(\theta_{0}\right)-\int_{0}^{\infty} c_{0}\left(\theta_{0}\right) d F\left(\theta_{0}\right)\right)
$$

Where in previous : $K_{1}=e_{0}+\int_{0}^{\infty} n_{0}\left(\theta_{0}\right) d F\left(\theta_{0}\right)-\int_{0}^{\infty} c_{0}\left(\theta_{0}\right) d F\left(\theta_{0}\right) \geq 0$; it is imposed $R=G^{\prime}\left(K_{1}\right)$., now letting $\phi\left(\theta_{0}\right) d F\left(\theta_{0}\right)$ be the multiplier of inequality, FOC now implies altogether with strictly positive consumption:

equation 34

$$
\frac{\tau\left(\theta_{0}\right)}{1+\tau\left(\theta_{0}\right)}=\max \left\{0,-\frac{1}{\beta} \frac{v}{\mu} u^{\prime}\left(c_{0}, \theta_{0}\right)-\beta \frac{G^{\prime \prime}\left(K_{1}\right)}{\lambda} \int \frac{\phi\left(\theta_{0}\right)}{u^{\prime}\left(c_{0}, \theta_{0}\right)} d F\left(\theta_{0}\right)\right\}
$$

Where $R=G^{\prime \prime}\left(K_{1}\right)$ are the pre-tax returns. When one parent lowers bequests that in turn lowers aggregate capital $K_{1}$ which raises the pretax return $R=G^{\prime}\left(K_{1}\right)$, this effect is present when $G^{\prime \prime}\left(K_{1}\right)<0$. In a 
Mirrleesian framework with infinite horizon an individual born in period $t$ has ex-ante welfare $v_{t}$ which is equal to:

equation 35

$$
v_{t}=\mathbb{E}_{t-1}\left[u\left(c_{t}\right)-h\left(\frac{n_{t}}{\theta_{t}}\right)+\beta v_{t+1}\right]=\sum_{s=0}^{\infty} \beta^{s} \mathbb{E}_{t-1}\left[u\left(c_{t+s}\right)-h\left(\frac{n_{t+s}}{\theta_{t+s}}\right)\right]
$$

$\beta<1$ is the altruism coefficient, and that utility function satisfy Inada conditions namely: $u^{\prime}(0)=$ $\infty ; u^{\prime}(\infty)=0 ; h^{\prime}(0)=0, h^{\prime}(\bar{n})=\infty$ where $\bar{n}$ is the upper bound on work effort, $h$ is a disutility function. In ths economy aggregate consumption and employment are described as follows: $C_{t} \equiv \int_{0}^{\infty} \sum_{\theta^{t}} c_{t}^{v}\left(\theta^{t}\right) \theta^{t} d \psi(v)$ and $N_{t} \equiv \int \sum_{\theta^{t}} n_{t}^{v}\left(\theta^{t}\right)\left(\theta^{t}\right) d \psi(v)$. The idea is to devise a tax policy that induces all agents to be truthful and to bequeath $b_{t}=K_{t}$. And following Kocherlakota (2005) Farhi and Werning (2010) set the linear tax on inherited wealth:

equation 36

$$
\hat{\tau}_{t}^{v}\left(\theta^{t}\right)=1-\frac{1}{\beta R_{t-1, t}} \frac{u^{\prime}\left(c_{t-1}^{v}\left(\theta^{t-1}\right)\right)}{u^{\prime}\left(c_{t}^{v}\left(\theta^{t}\right)\right)}
$$

The average inheritance tax is $: \bar{\tau}_{t}\left(v_{t}\right)=-\frac{v_{t}}{\mu_{t-1}} u^{\prime}\left(c_{t-1}\left(v_{t}\right)\right)$.In the Atkeson-Lucas(1992) framework when $\underline{V}=V^{*}$; future generations are taken into account only through the altruism of first generation, where welfare associated with misery $V^{*} \equiv(u(0))-\frac{\mathbb{E}\left(\left[h\left(\frac{n}{\theta}\right]\right]\right)}{1-\beta}$.

\section{Henry George theorem and the optimum size of town (Arnott, Stiglitz (1977))}

Now, with the money raised from the land taxes public goods can be financed in some town that ought to have optimal size. That is famous Henry George theorem. Henry George had famously advocated for the replacement of all other taxes with a land value tax, arguing that as the location value of land was improved by public works, its economic rent was the most logical source of public revenue. Or as Arnott, Stiglitz (1977) define somewhat:..."in a simple spatial economy, where the spatial concentration of economic activity is due to a pure local public good and where population size is optimal, aggregate land rents equal expenditure on the pure public good..”. This result has been dubbed HGT or Henry George theorem. Since ".... a confiscatory tax on land rents is not only efficient, it is also the "single tax" necessary to finance the pure public good". Shortly will follow the basic setup of the model that includes:

equation 37

$$
R^{\prime}(t)=-f^{\prime}(t) ; A L R=\int_{0}^{t^{*}} R(t) 2 \pi t d t ; A T C=\int_{0}^{t^{*}} f(t) 2 \pi t d t
$$

Where $t$ is the distance to the towns center; $R(t)$ is the rent per unit of land, $f(t)$ are the transport costs to the center of the town, as we move away form the center $d t$-lot rent is decreased $-R(t) d t$, costs are transport costs growth; $f^{\prime}(t) d t$. By integration and substitution we get:

equation 38

$$
\int_{0}^{t^{*}}-R^{\prime} \pi t^{2} d t+R\left(t^{*}\right) \pi t^{* 2}=\int_{0}^{t^{*}} f^{\prime} \pi t^{2} d t+R\left(t^{*}\right) \pi t^{*} 2
$$

First part is differential rent $D L R$ investor that builds on better land has higher rent equation 39

$$
D L R=\frac{1}{2} A T C f^{\prime} t=f, \forall t
$$

Population of the town with radius $t^{*}$ is $N\left(t^{*}\right)=\pi t^{* 2}$ transport costs per unit land $e$ are: ATC = $e \int_{0}^{t^{*}} t(2 \pi t) d t=\frac{2 e}{3} \pi t^{* 3}$ and $A T C=k N^{\frac{3}{2}}$ where $k=\frac{2}{3} e \pi^{-\frac{1}{2}}$. Resources are proportional to population $Z=I N$, cost of resources are $P$, per capita consumption of public good $C$ where: $C=I-\frac{A T C}{N}-\frac{P}{N}$; and $C=I=k N^{\frac{1}{2}}-\frac{P}{N}$ ; where $P=\frac{1}{2} k N^{\frac{3}{2}}$ and $P=\frac{1}{2} A T C=D L R$. Public expenditures are $1 / 2$ transport costs that equal differential rent, $R C=A E+P+A T C$. Resource costs $R C$ are equal to aggregate expenditures + pubic good costs +average transport costs $A T C$.Average resource costs $\overline{R C}$ are equal to: $\overline{R C}=C+\frac{P}{N}+\frac{A T C}{N}$. Marginal resource costs are equal to $M R C=C+f\left(t^{*}\right)$. If everybody has equal size lots and no land-scarcity each resident land rent and transport costs are equal for all residents $f\left(t^{*}\right)$ and are:

$$
\begin{aligned}
& \text { equation } 40 \\
& f\left(t^{*}\right)=\frac{A L R}{N}+\frac{A T C}{N} ; M R C=C+\frac{A L R}{N}+\frac{A T C}{N}
\end{aligned}
$$

In a town with sub-optimal population public goods expenditures exceeds aggregate land rent, while in town with super optimal size is vice versa $P \gtreqless A L R ; N \lesseqgtr N^{*}$. When there is no land scarcity and with identical 
individuals $U(C, T, P)$, where $C$ is a consumption of public good, $T$ is land consumption, $P$-is a expenditure on public good equal to the supply of public good. And, $U(t)=(C(t), T(t), P)$ is the utility for the individuals with distance $t$ from the center. Here we want to maximize:

inequality 7

$$
\int_{0}^{t^{*}} \frac{W(U(t))}{N(t)} \phi(t) d t
$$

Where $W$ is a social welfare function, $\phi(t) d t$ is the area of the residential land form the center to $t \rightarrow d t$ , $\phi(t)$-is the shape of the town, $\phi(t)=2 \pi t$ means that the town is circle, $\phi(t)=w$ means that the town is linear. All individuals are located somewhere and all lad is used:

equation 41

$\int_{0}^{t^{*}} \frac{\phi(t)}{T(t)} d t=N ; \int_{0}^{t^{*}} \frac{f(t)+C(t)}{T(t)} \phi(t) d t+P=N I$

$I$-are the per capita resources. This can be expressed as standard Pontryagin problem, the Lagrangean of which is:

equation 42

$$
\mathcal{L}=\int_{0}^{t^{*}} \frac{W(U(t))}{N(t)} \phi(t) d t+\lambda\left(\int_{0}^{t^{*}} \frac{\phi(t)}{T(t)} d t-N\right)-\Omega\left(\int_{0}^{t^{*}} \frac{f(t)+C(t)}{T(t)} \phi(t) d t+P-N I\right)
$$

Hamiltonian is given as: $H=\left[\frac{W(U(C, T, P)}{N}+\lambda=\Omega(f+C)\right] \frac{\phi}{T}$; marginal utility for all individuals is $: \frac{\partial H}{\partial C}=$ $\left(\frac{W^{\prime} U_{C}}{N}-\Omega\right) \frac{\phi}{T}=0$. Marginal social utility of allocating more land on individuals by the given distance from the town center must be equal to marginal costs :

equation 43

$$
\frac{\partial H}{\partial T}=-\frac{\phi}{T^{2}}\left[\frac{W(U)}{N}+\lambda-\Omega(f+C)\right]+\frac{W^{\prime} U_{T}}{N T} \phi=0
$$

Condition for optimal supply of public goods says that the marginal rate of substitution of public and private goods must be equal to the marginal rate of transformation:

equation 44

$$
\frac{\partial \mathcal{L}}{\partial P}=\int_{0}^{t^{*}} \frac{W^{\prime} U_{P}}{N T} \phi d t-\Omega=0 ; \int_{0}^{t^{*}} \frac{U_{P}}{U_{C}} \frac{\phi}{T} d t=1
$$

Now about the optimal size of the town, I must be that :marginal social benefit from the population growth (from the in creasing availability of resources); must be equal to the marginal social costs (costs of private goods +transport cost for the marginal individual+ plus the crowding costs imposed by the marginal individual)

$$
\begin{aligned}
& \text { equation } 45 \\
& \frac{\partial \mathcal{L}}{\partial N}=-\int_{0}^{t^{*}} \frac{W(U)}{N^{2} T} \phi d t-\lambda+\Omega I=0 ; \dot{P}=\int_{0}^{t^{*}} \frac{U_{T}}{U_{C}} \phi d t
\end{aligned}
$$

Proof of the HGT: Now when the land is scarce; the average population density is $\frac{1}{\eta}$ and we have that $: \int_{0}^{t^{*}} \phi d t=\eta N$; Lagrange multiplier is :

equation 46

$$
\frac{\partial \mathcal{L}}{\partial t^{*}}=\frac{\phi\left(t^{*}\right)}{T}\left[\frac{W(U)}{N}+\lambda-\Omega(f+C)\right]_{t^{*}}-\mu \phi\left(t^{*}\right)=0
$$

Where $\mu=\frac{\left(W^{\prime} U_{T}\right)_{t^{*}}}{N}=\left(\frac{\Omega U_{t}}{U_{C}}\right)_{t^{*}} ; \Omega$-e is the social marginal benefit of the private good; and $P=$ $\int_{0}^{t^{*}} \frac{U_{T}}{U_{C}} \phi d t-\left(N \frac{\eta U_{T}}{U_{C}}\right)_{t^{*}}$. Now about the generality of the HGT we have: gradient of the relative population is $D(t) ; \int_{0}^{t^{*}} D(t) \phi(t) d t=1$, where $\phi(t)$ represents towns shape, resource costs per capita are: $\frac{1}{N}\left(\int_{0}^{t^{*}}(C+\right.$ f) $\left.N D_{\phi} d t+P\right)$. Planers problem is :

inequality 8

$$
\min \frac{1}{N}\left(\int_{0}^{t^{*}}(C+f) N D_{\phi} d t+P\right)
$$

s.t. $U(\theta(t))=U(t)$, FOC gives: $\int_{0}^{t^{*}} \frac{d C}{d N} D_{\phi} d t-\frac{P}{N^{2}}=0$. Requirement for the utility on any available location not to be changed by the population change is:

equation 47

$U_{C} \frac{d C}{d N}+U_{T} \frac{d T}{d N}=0, \forall T ; T=\frac{1}{N D} ; \frac{d T}{d N}=\frac{d\left(\frac{1}{N D}\right)}{d N}=-\frac{1}{N^{2} D} ; \frac{1}{N} \int_{0}^{t^{*}}(C+f) N D_{\phi} d t+\frac{1}{N} \int_{0}^{t^{*}} \frac{U_{T}}{U_{N}} \phi d t$ 
Average costs are given as: $\frac{1}{N} \int_{0}^{t^{*}}(C+f) N D_{\phi} d t+\frac{P}{N}$; and in the optimum average costs of the resources equal to marginal resource costs that is Henry George theorem

Resource costs are given as: $\left.\overline{R C}=\frac{1}{N} \int_{0}^{t^{*}}\left(C^{*}+f\right) N D_{\phi} d t+\bar{R} \int_{0}^{t^{*}} \phi d t+P\right)$ where $P=D L R$ with optimal population instead $P=A L R$.In the towns with non-optimal size: $\overline{R C}=\int_{0}^{t^{*}}(C+f) N D_{\phi} d t+\frac{P}{N} ;$ where $\frac{d \overline{R C}}{d N}>0$ means that population is super optimal. And :

equation 48

$$
\frac{d \overline{R C}}{d N}=\int_{0}^{t^{*}} \frac{d C}{d N} D_{\phi} d t-\frac{P}{N^{2}}
$$

inequality 9

$\frac{d \overline{R C}}{d N}>0 \Leftrightarrow N>N^{*} \Leftrightarrow A L R>P ; \frac{d \overline{R C}}{d N}<0 \Leftrightarrow N<N^{*} \Leftrightarrow A L R<P$

In a super optimal town aggregate rent exceeds the expenditures on public goods:

equation 49

$\int_{0}^{t^{*}}\left(\frac{d C}{d N}+f_{N}\right) D_{\phi} d t-\frac{P}{N^{2}}=0 ; \int_{0}^{t^{*}} \frac{U_{T}}{U_{C}} \phi d t+\int_{0}^{t^{*}}\left(f_{N} N\right) N D_{\phi} d t=P$

Where $\int_{0}^{t^{*}}\left(f_{N} N\right) N D_{\phi} d t$-is the ACE or aggregate congestion externality it is the sum that will be raised in revenues from taxes if optimal tax rate is levied on the congestions.

inequality 10

$$
D L R+A C E=P \rightarrow N=N^{*} ; D L R+A C E>P \Leftrightarrow N>N^{*}, D L R+A C E<P \Leftrightarrow N<N^{*}
$$

Indirect utility is $V=V((1+\tau) R, Y, P)$ where: $Y$-is net income from transport costs, $P$ - is the level of public services, differences in public goods are infinitesimal $d V=V_{2}\left(=T(1+\tau) d R+\left(\frac{V_{3}}{V_{2}}\right) d P\right)$. Where $\frac{V_{3}}{V_{2}}$ - is the marginal benefit of the individual from public good in monetary terms: $V(R(t), I-f(t), A)=\bar{U} ; I$-is the gross income; A-amenities (local amenities) $A+d A$ in another municipality $\frac{d R}{d A}=\frac{V_{3}}{V_{2}} \frac{1}{T}$; so now the aggregate land rent is :

equation 50

$$
\mathrm{A} L R=\int_{0}^{t^{*}} R(t) \phi(t) d t ; V\left(\bar{R}, I-f\left(t^{*}\right), A\right)=\bar{U}
$$

Where following applies: $\frac{d A L R}{d A}=\int_{0}^{t^{*}} \frac{d R(t)}{d A} \phi(t) d t+R\left(t^{*}\right) \phi\left(t^{*}\right) \frac{d t^{*}}{d A} ; \frac{d A L R}{d A}-R\left(t^{*}\right) \phi\left(t^{*}\right) \frac{d t^{*}}{d A}=\frac{d D L R}{d A}$

equation 51

$\frac{d A L R}{d A}=\int_{0}^{t^{*}} \frac{d R(t)}{d A} \phi(t) d t ; \frac{d D L R}{d A}=\int_{0}^{t^{*}} \frac{V_{3}}{V_{2}} \frac{\phi}{T} d t$

Now about the different fiscal packages. Pure public good is obtained at constant costs and financed by means of rent tax where $V(R(t)(1+\tau), I-f(t), P)=\bar{U}$. Balanced budget requires: $\tau A L R=P$.

$$
\frac{\text { equation } 52}{d P}=\int_{0}^{t^{*}} \frac{V_{3}}{V_{2}} \frac{\phi}{T} d t-1 \quad ; \int_{0}^{t^{*}} \frac{V_{3}}{V_{2}} \frac{\phi}{T} d t>=<1
$$

Where $V\left(\frac{d R}{d P}(1+\tau)+R \frac{d \tau}{d P}\right)+V_{3}=0 ; \frac{d \tau}{d P} A L R+\tau \frac{d A L R}{d P}=1$ and by further simplification: equation 53

$$
\frac{d A L R}{d A}=\int_{0}^{t^{*}} \frac{d R}{d P} \phi d t
$$

$$
\begin{aligned}
& =\int_{0}^{t^{*}} \frac{d R}{d P} \phi d t \\
& =\int_{0}^{t^{*}}-\frac{V_{3} \phi}{V_{1}(1+\tau)} d t-\int_{0}^{t^{*}} \frac{R_{\phi}}{1+\tau} \frac{d \tau}{d P} d t=\int_{0}^{t^{*}} \frac{V_{3} \phi}{V_{2}(1+\tau) T} d t-\frac{A L R}{1+\tau}\left(\frac{1}{A L R}-\frac{\tau}{A L R} \frac{d A L R}{d P}\right) \\
& =\int_{0}^{t^{*}} \frac{V_{3}}{V_{2}} \frac{\phi}{T} d t-1 \\
& V(R(t)(1+\tau), I-f(t), e E)=\bar{U}
\end{aligned}
$$

Where $\tau A L R=\mathrm{P} ; \quad \frac{d A L R}{d e}=E \int_{0}^{t^{*}} \frac{V_{3}}{V_{2}} \frac{\phi}{T} d t$, where $E$ are the public goods expenditures, and $P=e E$ expenditures per unit land for supplying public goods. About the different individual rules:

equation 54

$$
V(\beta)=c(R(t), I-f(t))+\beta g(A)
$$


Where $\beta$ is the increasing valuation of amenities of public good $A$, and population is continuously distributed through $\beta$. Individual by $\beta=\hat{\beta}$ is indifferent whether he/she will live in a town with better or worse public goods. And these apply :

$$
\frac{d R(t)}{d A}=-\frac{\widehat{\beta} g^{\prime}}{v_{1}(t)} \quad v_{1}=-v_{2} T \frac{d R(t)}{d A}=\frac{\widehat{\beta} g^{\prime}}{v_{2} T(t)} ; \frac{d A L R}{d A}=\int_{0}^{t^{*}} \frac{\widehat{\beta} g^{\prime}}{v_{2} T} \phi d t ; \int_{0}^{t^{*}} \frac{\beta(t) g^{\prime} \phi}{v_{2} T} d t
$$

Optimal population is where resource costs $I$ equal marginal costs of the resources: $I=C+f(t)+$ $R(t) T$. Next theory of optimum town by Mirrlees (1972) will be explained.

\section{Optimum town (Mirrlees(1972))}

Utility function here is: $\int u(c, a, r) f(r) d r$, where $u$ - is the utility function; $a$ is the area occupied with livig space, $r$ is the distance to work, $f(r)$ is the population density of the distance $r$ from the town center, $c$ is the consumption. From previous $a(r) f(r)=1$, where $\int r f(r) d r=N$ is the town population, $\int c(r) f(r) d r=$ $Y$ is the output. Limits is $[0, \bar{r}]$. Maximum welfare is given as:

equation 56

$$
W(Y, N)=\max \int u(c(r), a(r), r) r f(r r) d r
$$

Effect from adding additional unit of consumption to the town is : $W_{Y}=u_{c}(c(r), a(r), r), f(r)>0$ and the effect of adding additional person to the town is: $W_{N}=u(c(r) . a(r), r)-c(r) u_{c}-a(r) u_{a}$. Here is will be defined that $: \lambda=W_{Y} ; \mu=W_{N} ; u_{c}=\lambda$. Now we are supposing that: $c=c(r) ; a=a(r) ; 0 \leq r<r_{1}$ and $\mathrm{u}(\mathrm{c}(0), 0,0) \leq \lambda \mathrm{c}(0)+\mu$. And that :

$$
\text { inequality } 11
$$

equation 57

$$
\begin{gathered}
n_{0}>0 \\
u(c, \infty, r) \leq \lambda c+\mu \\
\forall c>0, r>r_{1}
\end{gathered}
$$

$n_{0}+\int_{0}^{r_{1}} \frac{r d r}{a r}=N ; n_{0} c(0)+\int_{0}^{r_{1}} c(r) \frac{r d r}{a r}=Y$

Then the allocation is defined $c(\cdot) ; a(\cdot)$ is optimal and the number of people $n_{0}$ concentrated around $r=$ 0 is optimal. We are supposing that $a^{\prime}=0$ around $r=0$.Now we have about the population one inequality : inequality 12

Utility is constrained such that:

$$
\begin{gathered}
n_{0}[u(c(0), 0,0)-\lambda c(0)-\mu] \geq n^{\prime}{ }_{0}\left[u\left(c^{\prime}(0), 0,0\right)-\lambda c^{\prime}(0)-\mu\right] \\
\frac{u-\lambda c-\mu}{a} \geq \frac{u^{\prime}-\lambda^{\prime} c-\mu}{a^{\prime}} ; 0<r<1 \\
0 \geq \frac{u^{\prime}-\lambda^{\prime} c-\mu}{a^{\prime}}, r>r_{1}
\end{gathered}
$$

inequality 13

$$
\begin{gathered}
u\left(c^{\prime}(0), 0,0\right)-\lambda c^{\prime}(0) \leq u(c(0), 0,0)-\lambda c(0) \leq \mu ; \\
u^{\prime} \leq u+u_{c}\left(c^{\prime}-c\right)+u_{a}\left(a^{\prime}-a\right)=\mu+\lambda c^{\prime}+u_{a} a^{\prime} \\
n_{0} u(c(0), 0,0)+\int \frac{u r d r}{a(r)} \\
u_{a}=\frac{(u-\lambda c-\mu)}{a} \\
n_{0} u(c(0), 0,0)+\int u \frac{r d r}{a(r)}-\lambda Y-\mu N \geq n_{0}^{\prime} u\left(c^{\prime}(0), 0,0\right)+\int u^{\prime} \frac{r d r}{a(r)}-\lambda Y^{\prime}-\mu N^{\prime} \\
u_{r}+u_{c} \frac{d c}{d r}+u_{a} \frac{d a}{d r}=u_{a} \frac{d a}{d r}+a \frac{d}{d r} u_{a}+\lambda \frac{d c}{d r^{\prime}} \\
\frac{d}{d r} u_{a}=\frac{u_{r}}{a} \\
\frac{d a}{d r} u_{c}=0 \\
\frac{u_{a r}}{u_{r}}<\frac{u_{a r}}{u_{a r}}-\frac{u_{a a}}{u_{a}}=\frac{\partial}{\partial a} \log \left|\frac{u_{r}}{u_{a}}\right|
\end{gathered}
$$


$m$-is the distribution of incomes, $p$ - is the rent function, $p(r)$ is the price of land at distance $r$ ,maximization problem is: $\max (c, a, r)$ s.t. $c+p(r) a \leq m$ where $P D F_{m}=\int g(g(m) d m$. Consumer satisfies: inequality 14

$$
\begin{gathered}
\mathrm{u}_{a}=u_{c} p(r), u_{r}=u_{c} a p^{\prime}(r) ; p(r)=\frac{u_{a}^{*}}{u_{c}^{*}} ; m=c^{*}(r)+a^{*}(r) p(r) ; c+a p(s) \leq c^{*}(r)+a^{*}(r) p(r) \\
\begin{aligned}
u(c, a, s) \leq\left(c^{*}(s), a^{*}(s), s\right)+u_{c}^{*}(s)\left[c-c^{*}(s)\right]+u_{a}^{*}(s)\left[a-a^{*}(s)\right] \\
=\mu+\lambda c+u_{a}^{*}(s) a, \\
=\mu+\lambda c+\lambda p(s) a, \\
\leq \mu+\lambda c^{*}(r)+\lambda p(r) a^{*}(r) \\
=u\left(c^{*}(r), a^{*}(r), r\right) \\
u(m-a p(r), a, r) \\
v(c, x, r)=u\left(c, \frac{x}{p(r)}, r\right)
\end{aligned}
\end{gathered}
$$

inequality 15

$$
\begin{gathered}
\max _{z} v(m-x, x, r) \\
u=v(c, a z(r)) \\
v_{c}=\lambda, v-c v_{c}-a z v_{2}=\mu \\
v_{2}=\frac{d v}{d a z} \\
u=e^{k c} w(a, r) \\
u=v(c-t r)+w(a, r)
\end{gathered}
$$

equation 58

$$
\frac{d u}{d r}=\frac{w_{r}^{2}}{a w_{a a}}\left[\frac{\partial}{\partial a}\left(\frac{a w_{a}}{w_{r}}\right)-\frac{w_{a}}{w_{r}^{2}} v^{\prime} t\right]
$$

$2 \pi \mathrm{N}(\mathrm{r})$ - number of people who live at the smallest distance $r$ from the center of the town.

$\frac{k N(r)}{r}$-is a proportion of the circle with radious $r$ that has to be used for the road, $f(r)-$ is population density at distance $r$ on land not occupied by roads. The following applies:

\section{Equation 59}

We what to maximize:

$$
-N^{\prime}(r)=[r-k N(r)] f(r)
$$

inequality 16

$$
-\int u(c(r), a(r), r) N^{\prime}(r) d r
$$

s.t. production constraint: $-\int c(r) N^{\prime}(r) d r=Y$; we have to choose functions $c$ and $N$ for the integral to be stationary:

equation 60

$$
\int\left[u\left(c,-\frac{r-k N}{N^{\prime}}, r\right)-\lambda c\right] N^{\prime} d r
$$

As before : $u_{c}=\lambda$, the Euler-Lagrange equation here it is: $\frac{d}{d r}\left[u-\lambda c-a u_{a}\right]=k u_{a}$.Now we are subjecting consumer with income $m$ to the budget constraint:

inequality 17

$$
c+p(r) a+\int_{r_{1}}^{r} k p(s) d s \leq m
$$

Now form this taxes commuter subsidies may be introduced ${ }^{38}$.

Commuter subsidy is $q(r)$. Person with income $m$ will maximize:

inequality 18

$u(c, a, r, f(r))$ s.t. $c+p(r) a \leq m+q(r)$

$p(r)=u_{a}^{*} / u_{c}^{*}$-is the marginal rate of substitution of the goods for land. And the derivation of the commuter subsidy is:

$$
\begin{aligned}
& \text { equation } 61 \\
& u_{r}+u_{f} f^{\prime}(r)=u_{c}\left[a p^{\prime}(r)-q^{\prime}(r)\right] ; \\
& u_{c}^{*} q^{\prime}(r)=a \frac{d}{d r} u_{a}^{*}-u_{r}^{*}-u_{f}^{*} f^{\prime}(r) ; \\
& u_{r}^{*}-a^{*}(r) \mid \frac{d}{d r} u_{a}^{*}+2 f^{\prime}(r) u_{f}^{*}+f(r) \frac{d}{d r} u_{f}^{*}=0 ;
\end{aligned}
$$

\footnotetext{
${ }^{38}$ Subsidized commuting" is defined by BLS as providing full or partial payment for the cost of an employee's commute to work via public transportation, a company sponsored van pool, discount subway fares, or bus tokens. Use of a company car does not qualify as subsidized commuting
} 


$$
u_{c}^{*} q^{\prime}(r)=f^{\prime}(r) u_{f}^{*}+f(r) \frac{d}{d r} u_{f}^{*}=\frac{d}{d r}\left(f u_{f}^{*}\right)
$$

equation 62

Optimization gives:

$$
q(r)=\frac{f^{*}(r) u_{f}^{*}}{u_{c}^{*}}
$$

inequality 19

$$
\begin{gathered}
u(c, a, s, f(s)) \leq u\left(c^{*}(s), a^{*}(s), s, f(s)\right)+\left[c-c^{*}(s)\right]+\left[a-a^{*}(s)\right] u_{a}^{*}(s) \\
=-f^{*}(s) u_{f}^{*}(s)+\mu+\lambda c+\lambda p(s) a=\mu+\lambda[c+p(s) a-q(s)] \leq \mu+\lambda m \\
u(c, a, s, f(s)) \leq u\left(c^{*}(r), a^{*}(r), r, f^{*}(r)\right)
\end{gathered}
$$

Where : $\lambda q^{\prime}(r)=f^{\prime}(r) u_{f}+f(r) \frac{d}{d r} u_{f} ; u=v_{1}(c-t r)+v_{2}(r)+w(a, f)$ and about the change in income distribution:

equation 63

$$
\lambda q^{\prime}(r)=\left(w_{f}+f w_{f f}-a w_{a f}\right) f^{\prime}(r)=\frac{\left(w_{f}+f w_{f f}-a w_{a f}\right)\left(v_{2}^{\prime}-t \lambda\right)}{a^{3} w_{a a}-2 a w_{a f}+f w_{f f}-2 w_{f}}
$$

If the production function is given as: $Y=H(N)$; production per capita is : $h=H^{\prime}(0) ; W(Y, N, B) ; B$-is the area covered by the town. Problem of the optimum geography is set as follows:

equation 64

$n W(C, N, B)+(P-n N) u\left(c_{0}, a_{0}, 0,1 / a_{0}\right)$-country dwellers enjoy consumption $c_{0}$ and area $a_{0}$ inequality 20

$n C+(P-n N) c_{0} \leq n H(N)+(P-n N) h$-consumption constraint

inequality 21

$n B+(P-n N) a_{0} \leq A$-area constraint

equation 65

$W_{C}=u_{c}^{0} ; W_{B}=u_{a}^{0}-a_{0}^{-2} u_{f}^{0} ; W_{N}=u^{0}-W_{C}\left(c_{0}+H^{\prime}-h\right)-W_{B} a_{0}$ constraints

equation 66

$W-N W_{N}-C W_{C}-B W_{B}+\left(H-N H^{\prime}(N)\right) W_{C}=0-n N$ remains constant; where $W_{B}$-is the value of the land added on the town periphery. We know that withing a town:

equation 67

$$
u-\lambda c-\lambda p(r) a+\lambda q(r)-\mu=0
$$

If we multiply previous by $r f(r)$ and integrate with respect to $r$ from zero to the boundary of the town we get:

equation 68

$$
W-\lambda C-\lambda \int p r d r+\lambda \int q r f d r-\mu N=0
$$

Combining previous two we get:

equation 69

$$
N H^{\prime}-H=\int\left(p-p^{0}\right) r d r-\int\left(q^{f}-\frac{q^{0}}{f^{0}}\right) r f d r
$$

Where $p^{0}=\frac{u_{a}^{0}}{\lambda}$-is the price of the rural land, $q^{0}=a_{0}^{-1} u_{f}^{0} / \lambda$-is the basis of the commuter subsidy .One can state that: Marginal product - Average product $=$ Average excess rent per man -Average excess commuter subsidy per man.

\section{A theory of optimal capital taxation (Piketty, Saez (2012))}

Here we will introduce just the most important equations from this paper Piketty, Saez (2012) in order to see how bequest enter into the capital tax equation, so that this debate makes more sense. In this model individuals maximize:

$$
\begin{aligned}
& \text { equation } 70 \\
& \begin{array}{c}
\max V_{t i}=V_{i}\left(c_{t i}, w_{t i}, \bar{b}_{t+1 i}\right) \\
\text { s.t. } c_{t i}+w_{t i} \leq \tilde{y}_{t i}=\left(1-\tau_{B}\right) b_{t i} e^{r H}+\left(1-\tau_{L}\right) y L_{t i} \text {. Where } \tilde{y}_{t i}=\left(1-\tau_{B}\right) b_{t i} e^{r H}+\left(1-\tau_{L}\right) y_{L_{t i}} \text { is total }
\end{array}
\end{aligned}
$$
after-tax lifetime income combining after tax capitalized bequest $\left(1-\tau_{B}\right) b_{t i} e^{r H}$ and after tax labor income $\left(1-\tau_{L}\right) y_{L_{t i}}$ and where $b_{t i} e^{r H}=b_{t i}(1+R)$ this is capital bequest received=raw bequest $b_{t i}+$ return $R b_{t i} ; c_{t i}$ is consumption, $w_{t i}$ is the end of life wealth ; $b_{t+1 i}$ is the pre tax raw bequest left to the next generation, $\bar{b}_{t+1 i}=$ $\left(1-\tau_{B}\right) b_{t+1 i} e^{r H}$ is after tax capitalized bequest left to the next generation, $\tau_{B} \geq 0$ is the tax rate on capitalized bequest, $\tau_{L} \geq 0$ is the tax rate on labor income. $V_{i t}$ is the utility function assumed to be homogenous of degree one to allow for balanced growth, and heterogenous individuals. Now production function is Cobb-Douglas: 
$V_{i}(c, w, \bar{b})=c^{1-s_{i}} w^{s_{w_{i}}} \bar{b}^{s_{b_{i}}} ; s_{w_{i}} \geq 0 ; s_{b_{i}} \geq 0 ; s_{i}=s_{w_{i}}+s_{b_{i}} \leq 1$. Where $s_{b_{i}}=s_{i}\left(1-\tau_{B}\right) e^{r H} \frac{V_{i \bar{b}}}{V_{i c}} ;$ and $s_{w_{i}}=s_{i} \cdot \frac{V_{i w}}{V_{i c}}$; these are the tastes for bequest and wealth respectively, and $V_{i c}=V_{i w} \cdot\left(1-\tau_{B}\right) e^{r H} V_{i \bar{b}}$; this is the FOC for an individual. $H$ represents the generation length, $N_{t}$ is the total population, per capita variables are $y_{t} \cdot k_{t} \cdot l_{t}, b_{t}$.Now, if $h_{t}$ is per capita productivity, then $l_{t}=\int_{i \in N_{t}} l_{t i} h_{t i} d_{i}$ (raw supply of labor), generations rate of return is $R=e^{r H}-1$; capital input is chosen so $F_{k}=R$; and $k_{t}=\beta^{\frac{1}{1-a}} l_{t}$; where $\beta=\frac{k_{t}}{y_{t}}=\frac{\alpha}{R}$ or capital to output ratio. Bequest transition is :

equation 71

$$
b_{t+1 i}=\left[\left(1-\tau_{L}\right) y_{L_{t i}}+\left(1-\tau_{B}\right) b_{t i} e^{r H}\right]
$$

Tastes for savings are $: s_{t i}=s_{w_{t i}}+s_{b_{t i}}$; the annual capita to output ratio is $: \beta=H \cdot \beta=\alpha\left(\frac{H}{R}\right)=\alpha$. $\frac{H}{e^{r H}-1} \simeq \frac{\alpha}{r}$. Capitalized bequest flow to output is $b_{y_{t}}=\frac{e^{r H} b_{t}}{y_{t}}$; so now transition equation for bequests is given as:

equation 72

$$
b_{y t+1}=\left(1-\tau_{L}\right)(1-a) e^{(r-g) H}+s\left(1-\tau_{B}\right) e^{(r-g) H} b_{y t}
$$

Government budget constraint in the optimal tax problem look like: $\tau_{L} y_{L_{t}}+\tau_{B} b_{t} e^{r H}=\tau y_{t}$ i.e. $\tau_{L}(1-$ $\alpha)+\tau_{B} b_{y}=\tau$. Taxation of capital would be:

equation 73

$$
\tau_{k}=\frac{\tau_{B}(1+R)}{R}
$$

$\tau_{B}$ is taxation on bequests, social welfare function to be maximized by the government is given as: equation 74

$$
S W F=\iint_{z \geq 0 ; \theta \geq 0} \omega_{p_{z} p_{\theta}} \frac{V_{z \theta}^{1-\Gamma}}{1-\Gamma} d z d \theta
$$

Where $V_{z \theta}=E\left(V_{i} \mid z_{i}=z ; \theta_{i}=\theta\right)$; where $z_{t i}=b_{t i} / b_{t}$, and $\phi(z)$ is the distribution of normalized bequest within cohort $t$. Aggregate savings rate is $: s=E\left(s_{i}\right)=p s_{i}$, where $p$ os probability. And: equation 75

$$
z=z_{k}=\frac{1-\mu}{p}+\frac{\mu}{p} \cdot z_{k+1}=\frac{1-\mu}{1-p} \cdot\left[\left(\frac{\mu}{p}\right)^{k}-1\right]
$$

Where: $\mu=s\left(1-\tau_{B}\right) e^{(r-g) H} ; \mu_{1}=s\left(1-\tau_{B}\right) e^{(r-g) H}=\frac{\mu}{p} ; z_{i}=z$ is the normalized inheritance, and productivity $\theta_{i}=\theta$.Long run inheritance elasticity is : equation 76

$$
e_{B}=\frac{\left(1-\tau_{B}\right)}{b_{y}} \frac{d b_{y}}{d\left(1-\tau_{B}\right)}
$$

In general, $e_{B}>0$ with higher net-tax rate $1-\tau_{b}$. Steady -state formula for $b_{y}$ is given as: equation 77

$$
b_{y}=\frac{s(1-\alpha-\tau) e^{(r-g) H}}{1-s e^{(r-g) H}}
$$

In the case of linear SWF $\Gamma=0$ and welfare weights $\omega_{p_{z} p_{\theta}}=1$ if $p_{z}=0$.For a zero receiver bequest optimum is:

equation 78

$$
\tau_{B}=\frac{1-(1-\alpha-\tau) s_{b 0} / b_{y}}{1+e_{B}+s_{b 0}} \quad \tau_{L}=\frac{\tau-\tau_{B} b_{y}}{1-\alpha}
$$

Here $\omega_{p_{z} p_{\theta}}=1$ if $p_{z}>0$ and $\Gamma=0$. A higher bequest elasticity $e_{B}$ unsurprisingly implies a lower $\tau_{B}$. As $e_{B} \rightarrow+\infty ;, \tau_{B} \rightarrow 0 \%$. I.e. one would never tax an infinitely elastic tax base as in the dynastic model of Chamley-Judd. Chamley (1986) and Judd (1985) show that the optimal capital income tax would be zero in the long run. For a $p_{z}$ bequest receiver; $\omega_{p_{z} p_{\theta}}=1$ if $p_{z}>0$ and $\omega_{p_{z}^{\prime} p_{\theta}}=1$ if $p_{z}^{\prime} \neq p_{z}, z$ is normalized inheritance for the $p_{z}$ receivers:

equation 79

$$
\begin{aligned}
& \tau_{B}=\frac{\frac{1-(1-\alpha-\tau) s_{b z}}{b_{y}}-\frac{\left(1-e_{B}+s_{b z}\right) z}{\theta_{z}}}{1+e_{B}+s_{b 0}} \\
& \tau_{L}=\frac{\tau-\tau_{B} b_{y}}{1-a}
\end{aligned}
$$

Where $s_{b z}=E\left(s b_{i} \mid p_{z i}=p_{z}\right)$ is the average bequest taste for $p_{z}$ receivers $\theta_{z}=E\left(\theta_{i} \mid p_{z i}=p_{z}\right)$ average productivity of $p_{z}$ receivers, $p_{z} ; p_{\theta}$ are the percentile ranks. The more unequal distribution of inherited wealth, 
the higher the optimal tax rate. With full wealth equality, there is no point in taxing bequests in this model. Conversely, with infinite wealth inequality (almost everybody has zero wealth, and a vanishingly small fraction has all of it), then $p_{z} \rightarrow 1$; almost everybody wants the same bequest tax rate as zero receivers. Now for the non-linear optimum taxes government constraint is: $\tau_{L}(1-\alpha)+\tau_{B} b_{y}^{*}=\tau$; where $b_{y}^{*}=\frac{e^{r H_{B}} *}{y_{t}}$; is capitalized taxable bequests over domestic product, $b_{t}^{m}>b_{y}^{*}$ is the average bequest. Then the pareto parameter is $: a=$ $\frac{b_{t}^{m}}{b_{t}^{m}-b_{t}^{*}} ;$ where $B_{t}^{*}=p^{*} \cdot b_{t}^{*} \cdot a /(a-1)$. Now for the elasticity of taxable bequests $e_{B}^{*}$ with respect to $\left(1-\tau_{B}\right)$ : equation 80

$$
e_{B}^{*}=\frac{d b_{y}^{*}}{d\left(1-\tau_{B}\right)} \frac{1-\tau_{B}}{b_{y}^{*}}=a \cdot \bar{e}_{B}
$$

$\bar{e}_{B}$ is the average elasticity, which is weighted by the bequest size of individual bequests $b_{t i}>b_{t}^{*}$ .Nonlinear optimum tax for zero-bequest receivers is:

equation 81

$\tau_{B}=\frac{1-(1-\alpha-\tau) s_{b 0}^{*} / b_{y}^{*}}{1+e_{B}^{*}+s_{b 0}^{*}} \quad \tau_{L}=\frac{\tau-\tau_{B} b_{y}^{*}}{1-\alpha}$

With elastic labor supply the optimal tax formula would have become:

equation 82

$$
\tau_{B}=\frac{1-\left(1-\alpha-\tau \cdot\left(1+e_{L}\right)\right) s_{b 0} / b_{y}}{1+e_{B}+s_{b 0} \cdot\left(1+e_{L}\right)} \quad \tau_{L}=\frac{\tau-\tau_{B} b_{y}}{1-\alpha}
$$

This formula is similar to the inelastic case except that $e_{L}$ appears both in the numerator and denominator. Tax rate $\tau_{B} \uparrow e_{L} \uparrow$ if $\tau\left(1+e_{B}\right)+s_{b 0}(1-\alpha) \geq b_{y}$.

\section{A Simpler Theory of Capital Taxation (based on: Saez,Stantcheva, (2016))}

In this model introduced in this paragraph there is a continuous time model with wealth in the utility function. We study the case where utility is quasi-linear in consumption that allows us to transofrm the problem in a static taxation problem. Suppose individual i has utility $u_{i}(c, k, z)=c+a_{i}(k)-h_{i}(z)$ where $a_{i}(\cdot)$ is increasing and concave and $h_{i}(\cdot)$ is the standard disutility from labor. Agents have heterogeneous discount rates $\delta_{i}$. The discounted utility is:

equation 83

$$
V_{i}\left(\left\{c_{i}(t), k_{i}(t), z_{i}(t)\right\}\right)=\delta_{i} \int_{0}^{\infty}\left[c_{i}(t)+a_{i}\left(k_{i}(t)\right)-h_{i}(z(t))\right] e^{-\delta, t} d t
$$

Motion of capital is :

equation 84

$$
\frac{d k_{i}(t)}{d t}=r k_{i}(t)+z_{i}(t)-T\left(z_{i}(t), r k_{i}(t)\right)-c_{i}(t)
$$

$T\left(z_{i}(t), r k_{i}(t)\right)$ is the tax paid by the individual $i$ and is dependent on income and capital returns. Wealth accumulation depends on the taste for wealth $a_{i}(\cdot)$ (assets) and in the impatience discount factor $\delta_{i}$. It also depends on the net tax return $\bar{r}=r\left(1-T_{k}\right)$; capital taxes discourage wealth accumulation through a substitution effect since there are no income effects. The Hamiltonian for the individual is:

equation 85

$$
\begin{aligned}
& H\left(c_{i}(t), k_{i}(t),(t), \lambda_{i}(t)\right) \\
& \quad=\left[c_{i}(t)+a_{i}\left(k_{i}(t)\right)-h_{i}(z(t))\right] e^{-\delta, t}+\lambda_{i}(t)\left[r k_{i}(t)+z_{i(t)}-T\left(z_{i}(t), r k_{i}(t)-c_{i}(t)\right]\right. \\
& \text { Taking the FOC: }
\end{aligned}
$$

equation 86

$$
\frac{\partial H_{i}}{\partial c}=e^{-\delta, t}-\lambda_{i}(t)=0 ; \frac{\partial H_{i}}{\partial z_{i}}=-h^{\prime}(z(t))^{e(-\delta, t)}+\lambda_{i}(t)\left[1-T_{z}\left(z_{i}(t), r k_{i}(t)\right]=-\lambda_{i}^{\prime}(t)\right.
$$$$
; \frac{\partial H_{i}}{\partial k_{i}(t)}=a_{i}^{\prime}\left(k_{i}(t)\right) e^{-\delta, t}+\lambda_{i}(t) r\left[1-T_{k}\left(z_{i}(t), r k_{i}(t)\right]=-\lambda_{i}^{\prime}(t)\right.
$$

By rearranging we get : $\lambda_{i}(t)=1 ; h^{\prime}(z(t))=1-T_{z}\left(z_{i}(t), r k_{i}(t) ; a_{i}^{\prime}\left(k_{i}(t)\right)=\delta_{i}-r(1-\right.$ $T_{k}\left(z_{i}(t), r k_{i}(t)\right)$.Lets denote that $\left(c_{i}, z_{i}, k_{i}\right)$ the steady state allocation. Now the objective function is following:

equation 87

$$
V_{i}\left(\left\{c_{i}(t), k_{i}(t), z_{i}(t)\right\}\right)=c_{i}+a_{i}\left(k_{i}\right)-h_{i}(z)+\delta_{i}\left(k_{i}^{\text {init }}-k_{i}\right)
$$

$k_{i}^{\text {init }}$ is the inherited level of capital; $\left(k_{i}^{\text {init }}-k_{i}\right)$ is the utility of cost of going from $k_{i}^{\text {init }}$ to the steadystate level. The government maximizes: 
equation 88

$$
S W F=\int_{i} \omega_{i} U_{i}\left(c_{i}, k_{i}, z_{i}\right) d i
$$

Where $\omega_{i}>0$ is the individual Pareto weight. The social marginal weight is: $g_{i}=\omega_{i} \cdot U_{i c}$. Optimal linear taxes on labor and capital respectively are $: \tau_{L} ; \tau_{k}$. The individual chooses labor and capital according to : $a_{i}^{\prime}\left(k_{i}\right)=\delta_{i}-\bar{r}$ and $h_{i}^{\prime}\left(z_{i}\right)=1-\tau_{L}$; where $\bar{r}=r\left(1-\tau_{k}\right)$.The government balances budget with lump-sum transfers for $G=\tau_{k} r k^{m}(\bar{r})+\tau_{L}$ where $z^{m}\left(1-\tau_{L}\right)=\int_{i} z_{i} d_{i}$ is the aggregate labor income, and $k^{m}(r)=\int_{i} k_{i}$ is the aggregate capital. Total consumption is $: c_{i}=\left(1-\tau_{k}\right) r k_{i}+\left(1-\tau_{L}\right) z_{i}+\tau_{k} r k^{m}(\bar{r})+\tau_{L} \cdot z^{m}\left(1-\tau_{L}\right)$ and the government now maximizes:

$$
S W F=\int_{i} \omega_{i}\left[\left(1-\tau_{k}\right) r k_{i}+\left(1-\tau_{L}\right) z_{i}+\tau_{k} r k^{m}+\tau_{L} \cdot z^{m}+a_{i}\left(k_{i}\right)-h_{i}\left(z_{i}\right)+\delta_{i} \cdot\left(k_{i}^{\text {init }}-k_{i}\right)\right] d i
$$

By using the envelope theorem we get:

equation 90

$$
\frac{d S W F}{d \tau_{k}}=\int \omega_{i}\left[-r k_{i}+r k^{m}+\tau_{k} r \frac{\partial k^{m}}{\partial \tau_{k}}\right]=r k^{m}\left[\int \omega_{i}\left(1-\frac{k_{i}}{k^{m}}\right) d i-\frac{\tau_{k}}{1-\tau_{k}} e_{k}\right]
$$

Where $e_{k}$ is the elasticity of aggregate capital with respect to the net of tax return $\bar{r}$.At the optimum where $\frac{d S W F}{d \tau_{k}}=0$ optimal linear tax is:

equation 91

$$
\tau_{k}=\frac{1-\bar{g}_{k}}{1-\overline{\bar{g}}_{k}+e_{k}}
$$

Where $\bar{g}_{k}=\int_{i} g_{i} k_{i} / \int_{i} k_{i}$ ].Now in the case of optimal nonlinear taxes, the individual budget constraint is : $c_{i}=r k_{i}-T K\left(r k_{i}\right)+z_{i}-T L\left(z_{i}\right)$, now we will define $\bar{G}_{k}(r k)$, the average relative welfare weight on individuals with capital income higher than $r_{k}$.

equation 92

$$
\bar{G}_{k}(r k)=\frac{\int_{\left(\left\{i: r k_{i} \geq r k\right\}\right)} g_{i} d_{i}}{P\left(r k_{i} \geq r k\right)}
$$

Let $h_{k}(r)$ be the distribution of capital income so that the Pareto parameter associated to the capital income distribution is given as: $\alpha_{k}(r k)=\frac{r k \cdot h_{k}(r k)}{1-H_{k}(r k)}$ where $e_{k}(r k)$ is the elasticity with respect to the net tax return $r\left(1-T_{k}^{\prime}(r k)\right)$. Government introduces small reform $\delta T_{K}(r k)$ where the marginal tax rate is increased by $\delta \tau_{k}$ in a small interval of capital income from $r k \rightarrow r k+d(r k)$. The mechanical effect associated with the reform is : $d(r k) \delta \tau_{k}\left[1-H_{k}(r k)\right]$. The welfare effect just weights the mechanical effect by $\bar{G}(r k)$, the social marginal welfare weight associated to the capital incomes above $r k$.Individuals who face increase in tax rate change their capital incomes by $\delta(r k)=-\frac{e_{k} \delta \tau_{k}}{1-T_{k}^{\prime}(r k)}$ and there are $h_{k}(r k) d(r k)$ individuals in the window affected by the tax change. By summing up the three effects we find :

equation 93

$$
\frac{T_{k}^{\prime}(r k)}{1-T_{k}^{\prime}(r k)}=\frac{1}{e_{k}(r k)} \cdot \frac{1-H_{k}(r k)}{r_{k} \cdot h_{k}(r k)} \cdot\left(1-\bar{G}_{k}(r k)\right)
$$

By using the definition of Pareto parameter we derive:

equation 94

$$
T_{k}^{\prime}(r k)=\frac{1-\bar{G}_{k}(r k)}{1-\bar{G}_{k}(r k)+\alpha_{k}(r k) \cdot e_{k}(r k)}
$$

\section{Conclusion}

This paper is a survey of a set of models on: Bequest taxation, estate taxation, land taxation, optimum town, Henry George theorem and capital taxation. Inequality arises with the size of the bequests, and the temptation or probability to undertake wealth reform increases with $R G^{-1}$ credibility constraint is tied to higher values of $R G^{-1}$,Farhi,Werning (2014). Stiglitz (1978) argues that in the case of the balanced growth effects with $k$ constant, inheritance taxation does reduce inequality. But for the two-class model and for low values of the elasticity of substitution proportion of the capital in ownership of workers will decrease as a result of the taxation of bequest, but the capitalist share will increase. In Farhi, Werning (2010), the implicit estate tax is strictly negative and increasing in the parent's productivity. This model augmented with endogenous fertility à la Becker, Barro (1988) gives result that marginal tax rates in this model should be negative and progressive. In the HGT paper by Arnott, Stiglitz (1977) Optimal population is where resource costs equal marginal costs of the 
resources. While in the optimum town by Mirrlees (1972), optimum town size is determined where Marginal product - Average product $=$ Average excess rent per man -Average excess commuter subsidy per man. In Piketty, Saez (2012), the more unequal distribution of inherited wealth, the higher the optimal tax rate. In Saez,Stantcheva, (2016), taxation of capital is progressive with higher the average relative welfare weight on individuals with capital income higher than $r_{k}$.More importantly rate of return on capital vary with individuals, with extent that is not optimally diversified, capital income taxation could be potentially desirable for the rate of return insurance reasons. Because of capital market imperfections, lifetime capital income and wealth taxation may be efficient way to implement optimal inheritance taxes. Higher values of $r-g$ lead to higher wealth inequality and with that to more progressive taxes on bequests. Taxes on the land estate and aggregate land rents (based on land value) that equal expenditures on public goods, could be used to collect higher revenues if government increase spending on certain public goods. Mirrlees (1972) concluded about inequality of income distribution that is desirable even when individuals are identical, when because of economies of scale production centers will be created but with the dispersed residence of workers. The optimum size of town can be characterized conveniently not uniquely by the simple relationship that the excess of marginal over average productivity in the central plant should equal the average excess of land rents (per head) over what they would have been in the absence of the town minus a correction if environmental externalities are present. In the case of environmental externalities presented as a case of a dependence of utility on local population density, commuter subsidies can help competitive equilibrium to be realized. These model in future we can combine so that we can empirically investigate the theoretical results that looked quite convincing.

\section{References}

1. Akerlof, G. A. (1978). "The Economics of "Tagging" as Applied to the Optimal Income Tax", Welfare Programs, and Manpower Planning, American Economic Review 68, 8-19.

2. Andreoni, J. (1989). "Giving with Impure Altruism: Applications to Charity and Ricardian Equivalence”. Journal of Political Economy, 97(6), 1447-1458. Retrieved July 14, 2021, from http://www.jstor.org/stable/1833247

3. Arnott, R. J., Stiglitz, J. E. (1979). “Aggregate Land Rents, Expenditure on Public Goods, and Optimal City Size”. The Quarterly Journal of Economics, 93(4), 471. doi:10.2307/1884466

4. $\quad$ Arnott,R.(2004). "Does the Henry George Theorem provide a practical guide to optimal city size?". The American Journal of Economics and Sociology. Retrieved 2007-11-03.

5. Arrow, K. (1951). “An extension of the basic theorems of classical welfare economics.” In Proceedings of the Second Berkeley Symposium on Mathematical Statistics and Probability, edited by J. Neyman, 507-532. University of California Press.

6. $\quad$ Atkeson, A. ,Lucas, Jr.R.E (1992) .’On Efficient Distribution with Private Information." Review of Economic Studies LIX(3) (1992), 427-453.

7. Atkinson, A., Sandmo,A. (1980). Welfare Implications of the Taxation of savings", The Economic Journal, 90, 529-549

8. Atkinson, A.B., and Joseph Stiglitz (1980). "Lectures on Public Economics", McGraw Hill. Beckert, Jens 2008. Inherited Wealth, Princeton University Press, 382p.

9. $\quad$ Atkinson, A.B.; Stiglitz,J.E. (1976).”The Design of Tax Structure: Direct vs. Indirect Taxation." Journal of Public Economics VI (1976), pp.55-75

10. Banks, J. and Diamond, P. (2010). "The Base for Direct Taxation", in The Mirrlees Review, Oxford University Press, Oxford, 548-648

11. Barro, R. J. (1974). "Are government bonds net wealth?" (PDF). Journal of Political Economy. University of Chicago Press via JSTOR. 82 (6): 1095-1117. doi:10.1086/260266. JSTOR 1830663

12. Becker, G. S.;. Barro,R.J. (1988).A Reformulation of the Economic Theory of Fertility." The Quarterly Journal of Economics CIII(1) (1988), 1\{25.

13. Benhabib,J. Bisin,A. Zhu,S.(2011). "The Distribution of Wealth and Fiscal Policy in Economies With Finitely Lived Agents", Econometrica, Vol. 79, No. 1 (January, 2011), 123-157

14. Cass, D. (1972), "On capital overaccumulation in the aggregative neoclassical model of economic growth: a complete characterization", Journal of Economic Theory, 4 (2): 200-223, doi:10.1016/00220531(72)90149-4

15. Chamley, C. (1986). "Optimal Taxation of Capital Income in General Equilibrium with Infinite Lives." Econometrica 54(3), 607-622.

16. Debreu, G. (1954). "Valuation equilibrium and Pareto optimum." Proceedings of the National Academy of Sciences 40 (7): 588-592

17. Diamond, P. A. (1965). "National Debt in a Neoclassical Growth Model," American Economic Review, 55(5): 1126-1150.

18. Farhi, E. Sleet,C. Werning,I.;Yeltekin,S. (2012)."Non-linear Capital Taxation Without Commitment," Review of Economic Studies, October 2012, 79 (4), 1469-1493. 
19. Farhi,E. Werning,I. (2010).” Progressive Estate Taxation” , The Quarterly Journal of Economics, Volume 125, Issue 2, May 2010, Pages 635-673, https://doi.org/10.1162/qjec.2010.125.2.635

20. Farhi,E. Werning,I. (2013).“Estate Taxation with Altruism Heterogeneity,” American Economic Review, 103 (3), pp.489-95.

21. Farhi,E. Werning,I. (2014). "Bequest Taxation and R-G," Working Paper 175926, Harvard University OpenScholar.

22. Farhi,E. Werning,I.(2010) "Progressive Estate Taxation," The Quarterly Journal

23. Gary-Bobo,R. J. ; Nur, J.(2015)." Housing, Capital Taxation and Bequests in a Simple OLG Model”. CEPR Discussion Paper No. DP10774.

24. George,H.(1879). "Progress and Poverty: An Inquiry into the Cause of Industrial Depressions and of Increase of Want with Increase of Wealth: The Remedy". Kindle Edition

25. Huber,B. (1996)."Optimale Finanzpolitik und zeitliche Inkonsistenz: Eine theoretische Analyse" (Studies in Contemporary Economics) (German Edition)

26. Ihori,T.(1997).'Taxes on Capital Accumulation and Economic Growth, Journal of Macroeconomics, Volume 19, Issue 3,Pages 509-522,

27. Johnson, C.E., J. Diamond ; G.R. Zodrow (1997). "Bequests, saving, and taxation", in: Proceedings of the Eighty-Ninth Annual Conference on Taxation, 1996 (National Tax Association, Washington, D.C.) pp. 3745 .

28. Judd, K. (1985). "Redistributive Taxation in a Simple Perfect Foresight Model." Journal of Public Economics, 28(1), 59-83

29. Kaplow, L. (2000).” A Framework for Assessing Estate and Gift Taxation”. NBER Working Paper No. w7775.

30. Keynes, J.M., (1920). "The economic consequences of the peace" (Harcourt, Brace and Howe).

31. Kocherlakota, N. (2005). "Zero Expected Wealth Taxes: A Mirrlees Approach to Dynamic Optimal Taxation." Econometrica LXXIII (2005), 1587\{1621.

32. Kotlikoff, L. ,Summers,L. (1981). "The Role of Intergenerational Transfers in Aggregate Capital Accumulation", Journal of Political Economy, Vol. 89, 1981, 706-732.

33. Krugman, P.(2019) "Elizabeth Warren Does Teddy Roosevelt,” New York Times, January 28, 2019.

34. Mankiw;N.G. Summers,L. Zeckhauser R.J.(1989). "Assessing Dynamic Efficiency: Theory and Evidence". Review of Economic Studies. 56 (1). pp. 1-19.

35. Mirrlees, J. (1972). "The Optimum Town". The Swedish Journal of Economics, 74(1), 114-135. doi: $10.2307 / 3439013$

36. Mirrlees, J. A. (1971). "An Exploration in the Theory of Optimum Income Taxation". The Review of Economic Studies. 38 (2): 175-208. doi:10.2307/2296779. JSTOR 2296779

37. Modigliani, F. (1966). "The Life Cycle Hypothesis of Saving, the Demand for Wealth and the Supply of Capital". Social Research. 33 (2): 160-217. JSTOR 40969831.

38. Modigliani, F. (1976). "Life-cycle, individual thrift, and the wealth of nations," American Economic Review, 76(3), 297-313.

39. Modigliani, F. (1986). "Life cycle, individual thrift and the wealth of nations". American Economic Review 76 (3), 297-313

40. Modigliani,F.,Brumberg,R.H.(1954), "Utility analysis and the consumption function: an interpretation of cross-section data," in Kenneth K. Kurihara, ed., PostKeynesian Economics, New Brunswick, NJ. Rutgers University Press. Pp 388-436.

41. Moon,H.(1989). "Essays on the effects of fiscal policy on intergenerational transfers and redistribution". PhD dissertation University of Pennsylvania

42. Mućk,J.(2017)," Elasticity of substitution between labor and capital: robust evidence from developed economies", NBP Working Paper No. 271

43. of Economics, 125 (2), pp.635-673.

44. Phelps, E.S. (1961). "The Golden Rule of Accumulation: A Fable for Growthmen", American Economic Review, Vol. 51, p.638-43.

45. Piketty, T. (2010). "On the Long-Run Evolution of Inheritance: France 1820-2050", Working Paper, Paris School of Economics, 424p

46. Piketty, T. (2014)." Capital in the Twenty First Century", Harvard University Press

47. Piketty, T. Saez,E.(2012).” A Theory of Optimal Capital Taxation”.NBER working papers

48. Piketty, T. Saez,E.(2013).” A theory of optimal inheritance taxation” Econometrica, Vol. 81, No. 5, pp. $1851-1886$

49. Piketty, T., Postel-Vinay,G.,Rosenthal,J.L,(2014). "Inherited vs. Self-Made Wealth: Theory and Evidence from a Rentier Society (1872-1927)," Explorations in Economic History

50. Poterba,J.M.,Weisbenner,S.(2001). "The Distributional Burden of Taxing Estates and Unrealized Capital Gains at the Time of Death".NBER working papers series 
51. Saez, E. (2002). "The Desirability of Commodity Taxation under Non-Linear Income Taxation and Heterogeneous Tastes", Journal of Public Economics 83, 217-230.

52. Saez, E., Stantcheva,S.(2016). “A Simpler Theory of Optimal Capital Taxation.” NBER Working Paper 22664.

53. Solow,R.(2014). “Are we becoming an oligarchy? “.An interview

54. Stiglitz, J. (1978). Notes on Estate Taxes, Redistribution, and the Concept of Balanced Growth Path Incidence. Journal of Political Economy, 86(2), S137-S150. Retrieved July 9, 2021, from http://www.jstor.org/stable/1829760

55. $\quad$ Stiglitz, J. E. (1985). "Inequality and Capital Taxation", Working Paper, Stanford.

56. Weil, P. (1987). "Love Thy Children: Reflections on the Barro Debt-Neutrality Theorem", Journal of Monetary Economics, 19, 377-391.

57. Zou, Heng-Fu (1995). “The spirit of capitalism and savings behavior". Journal of Economic Behavior and Organization Vol. 28 (1995) 131 -143 